\title{
Enhanced CRFR1-Dependent Regulation of a Ventral Tegmental Area to Prelimbic Cortex Projection Establishes Susceptibility to Stress-Induced Cocaine Seeking
}

\author{
Oliver Vranjkovic, ${ }^{1}$-Erik C. Van Newenhizen, ${ }^{1}$ Michael E. Nordness, ${ }^{1}$ ○Jordan M. Blacktop, ${ }^{1}$ Luke A. Urbanik, ${ }^{1}$ \\ Jacob C. Mathy, ${ }^{1}$ Jayme R. McReynolds, ${ }^{1}$ Anna M. Miller, ${ }^{1}$ Elizabeth M. Doncheck, ${ }^{1}$ Tyler M. Kloehn, ${ }^{1}$ \\ [D Gwen S. Stinnett, ${ }^{2}$ Clayton H. Gerndt, ${ }^{1}$ Kyle D. Ketchesin, ${ }^{2}$ David A. Baker, ${ }^{1}$ Audrey F. Seasholtz, ${ }^{2}$ \\ and $\odot$ John R. Mantsch ${ }^{1}$ \\ ${ }^{1}$ Department of Biomedical Sciences, Marquette University, Milwaukee, Wisconsin 53233 and ${ }^{2}$ Molecular and Behavioral Neuroscience Institute, \\ Neuroscience Graduate Program, and Department of Biological Chemistry, University of Michigan, Ann Arbor, Michigan 48109
}

The ability of stress to trigger cocaine seeking in humans and rodents is variable and is determined by the amount and pattern of prior drug use. This study examined the role of a corticotropin releasing factor (CRF)-regulated dopaminergic projection from the ventral tegmental area (VTA) to the prelimbic cortex in shock-induced cocaine seeking and its recruitment under self-administration conditions that establish relapse vulnerability. Male rats with a history of daily long-access $(\mathrm{LgA} ; 14 \times 6 \mathrm{~h} / \mathrm{d})$ but not short-access $(\mathrm{ShA}$; $14 \times 2 \mathrm{~h} / \mathrm{d})$ self-administration showed robust shock-induced cocaine seeking. This was associated with a heightened shock-induced prelimbic cortex Fos response and activation of cholera toxin b retro-labeled VTA neurons that project to the prelimbic cortex. Chemogenetic inhibition of this pathway using a dual virus intersectional hM4Di DREADD (designer receptor exclusively activated by designer drug) based approach prevented shock-induced cocaine seeking. Both shock-induced reinstatement and the prelimbic cortex Fos response were prevented by bilateral intra-VTA injections of the CRF receptor 1 (CRFR1) antagonist, antalarmin. Moreover, pharmacological disconnection of the CRF-regulated dopaminergic projection to the prelimbic cortex by injection of antalarmin into the VTA in one hemisphere and the D1 receptor antagonist, SCH23390, into the prelimbic cortex of the contralateral hemisphere prevented shockinduced cocaine seeking. Finally, LgA, but not ShA, cocaine self-administration resulted in increased VTA CRFR1 mRNA levels as measured using in situ hybridization. Altogether, these findings suggest that excessive cocaine use may establish susceptibility to stress-induced relapse by recruiting CRF regulation of a stressor-responsive mesocortical dopaminergic pathway.

Key words: cocaine; CRF; dopamine; prefrontal; reinstatement; stress

\section{Significance Statement}

Understanding the neural pathways and mechanisms through which stress triggers relapse to cocaine use is critical for the development of more effective treatment approaches. Prior work has demonstrated a critical role for the neuropeptide corticotropin releasing factor (CRF) in stress-induced cocaine seeking. Here we provide evidence that stress-induced reinstatement in a rat model of relapse is mediated by a CRF-regulated dopaminergic projection from the ventral tegmental area (VTA) that activates dopamine D1 receptors in the prelimbic cortex. Moreover, we report that this pathway may be recruited as a result of daily cocaine self-administration under conditions of extended drug access/heightened drug intake, likely as a result of increased CRFR1 expression in the VTA, thereby promoting susceptibility to stress-induced cocaine seeking.

\section{Introduction}

Relapse to drug use remains a barrier to the effective treatment of cocaine addiction. Although a number of stimuli can evoke re- lapse, stress is a particularly problematic relapse trigger because of its unpredictable and often unavoidable nature. Stress-induced relapse can be investigated in rats using the self-administration/ 
reinstatement approach, in which the ability of a stressor, most commonly electric footshock, to re-establish extinguished cocainedirected lever pressing is assessed (Mantsch et al., 2016). Studies using this approach have begun to define the neurocircuitry and mechanisms that contribute to stress-related relapse and have demonstrated involvement of dopamine D1 receptor activation in the prelimbic cortex (Capriles et al., 2003; McFarland et al., 2004) and corticotropin releasing factor (CRF) activation of the CRF receptor 1 (CRFR1) in the ventral tegmental area (VTA; Blacktop et al., 2011). Based on these findings, a role for a CRFregulated dopaminergic projection from the VTA to the prelimbic cortex in stress-induced cocaine seeking has been proposed but has not been directly demonstrated.

The mesocortical dopamine system has long been known to be highly responsive to stress (Thierry et al., 1976; Reinhard et al., 1982; Deutch et al., 1985; Speciale et al., 1986). VTA dopamine neurons that project to the prelimbic cortex are activated by stressors, as measured ex vivo by Fos immunoreactivity or AMPA/ NMDA ratios using slice electrophysiology in neurons labeled by retrograde tracers injected into the prelimbic cortex (Deutch et al., 1991; Lammel et al., 2011). Although studies examining the regulation of mesocortical dopamine by VTA CRF have produced mixed results (Kalivas et al., 1987), reports that intracerebroventricular CRF increases dopaminergic neurotransmission in the prefrontal cortex (Dunn and Berridge, 1987; Lavicky and Dunn, 1993) and that CRF promotes excitation of VTA dopamine neurons via both presynaptic and postsynaptic mechanisms (Ungless et al., 2003; Korotkova et al., 2006; Riegel and Williams, 2008; Wanat et al., 2008; Beckstead et al., 2009; Hahn et al., 2009; Williams et al., 2014) suggest that stress-induced CRF release into the VTA may underlie increases in mesocortical dopamine release. Consistent with this possibility, Refojo et al. (2011) reported that selective deletion of CRFR1 in VTA dopamine neurons significantly reduced stress-induced increases in dopamine in the prefrontal cortex in mice.

Evidence that CRF regulation of mesocortical dopamine is responsible for stress-induced cocaine seeking is indirect. Stressinduced reinstatement is associated with elevated extracellular CRF in the VTA (Wang et al., 2005) and extracellular dopamine in the prelimbic cortex (McFarland et al., 2004) and VTA (reflecting somatodendritic release; Wang et al., 2005). Moreover, CRF receptor antagonism in the VTA prevents both stress-induced cocaine seeking (Wang et al., 2005; Blacktop et al., 2011) and increases in VTA dopamine (Wang et al., 2005), whereas stressinduced cocaine seeking is prevented by D1 receptor antagonism in the prelimbic cortex (Capriles et al., 2003; McFarland et al., 2004). In this study we more directly test the hypothesis that stress-induced reinstatement requires CRF regulation of a dopaminergic pathway from the VTA to the prelimbic cortex.

We have found that stress-induced cocaine seeking depends on the prior history of cocaine use. Under our experimental protocol, footshock induces reinstatement in rats with a history of long-access (LgA; $14 \times 6 \mathrm{~h} / \mathrm{d})$ but not short-access $(\mathrm{ShA} ; 14 \times 2$ $\mathrm{h} / \mathrm{d}$ ) cocaine self-administration (Mantsch et al., 2008). Moreover, cocaine seeking in response to intra-VTA CRF delivery is also only observed following self-administration under LgA conditions (Blacktop et al., 2011), suggesting that cocaine use promotes stress-induced cocaine seeking by recruiting CRF reg-

Correspondence should be addressed to Dr. John R. Mantsch, Department of Biomedical Sciences, Box 1881, Marquette University, Milwaukee, WI 53233-1881. E-mail: john.mantsch@marquette.edu.

https://doi.org/10.1523/JNEUROSCI.2080-18.2018

Copyright $\odot 2018$ the authors $\quad 0270-6474 / 18 / 3810658-15 \$ 15.00 / 0$ ulation of the mesocortical pathway. Although a role for VTA CRF receptor 2 (CRFR2) in stress-induced cocaine seeking has been reported (Wang et al., 2005), we and others have demonstrated a role for CRFR1 but not CRFR2 (Blacktop et al., 2011; Chen et al., 2014). Therefore, in the present study we also test the hypothesis that stressor regulation of the mesocortical dopamine pathway is recruited following LgA self-administration as a result of increased VTA CRFR1 expression.

\section{Materials and Methods}

Subjects. Adult male Sprague-Dawley rats (Envigo Laboratories) 90-dold at the time of delivery ( $300 \mathrm{~g}$ ) were housed individually in a temperature- and humidity-controlled, Association for Assessment and Accreditation of Laboratory Animal Care accredited facility under a $12 \mathrm{~h}$ dark/light cycle (lights off at $0700 \mathrm{~h}$ ) and had access to food and water ad libitum, except during food training periods within which they were maintained at $90 \%$ of their free-feeding bodyweight. All procedures were performed in accordance with the NIH Guide for the Care and Use of Laboratory Animals and were approved by the Institutional Animal Care and Use Committee (Marquette University).

Drugs. Cocaine $\mathrm{HCl}$ and clozapine $\mathrm{N}$-oxide $(\mathrm{CNO})$ were acquired from the National Institute on Drug Abuse through its Drug Supply Program. The selective dopamine D1 receptor antagonist, SCH-23390, and the CRFR1 antagonist, antalarmin, were purchased from SigmaAldrich. All drugs were dissolved in bacteriostatic $0.9 \%$ saline. CNO was dissolved in 5\% DMSO in saline. Intracranial drug doses were selected based on previously published results (Capriles et al., 2003; Blacktop et al., 2011; Vranjkovic et al., 2014).

Operant conditioning chambers. Operant conditioning chambers encased in sound-attenuating cubicles (MED-Associates) were used. A retractable lever and stimulus light were mounted on the front wall of each chamber. A second light and lever were located on the opposite wall. The grid floors of the chambers were connected to an aversive stimulator for shock delivery. Drug infusions were delivered via syringes mounted in motorized infusion pumps. The experimental chambers were interfaced with computers containing MED-PC software for device control and data collection.

Self-administration and extinction. Rats were surgically implanted with indwelling jugular catheters under ketamine $\mathrm{HCl}(100 \mathrm{mg} / \mathrm{kg}$, i.p. $)$ and xylazine $(2 \mathrm{mg} / \mathrm{kg}$, i.p.) anesthesia, as previously described (Blacktop et al., 2011; Vranjkovic et al., 2014). For analgesia, 1 d before surgery and for $4 \mathrm{~d}$ postsurgery, rats were allowed to ingest bacon-flavored $2 \mathrm{mg}$ carprofen tablets (Bio-Serv, Rodent MD's Rimadyl). Additionally, on the day of and for $4 \mathrm{~d}$ after surgery, rats received daily intravenous $200 \mu \mathrm{l}$ injections of the antibiotic, cefazolin ( $2 \mathrm{mg} /$ injection; Sagent Pharmaceuticals). Following a $5 \mathrm{~d}$ recovery period, rats were food-deprived to $90 \%$ of their free-feeding weight and trained to press a lever under a continuous schedule of sucrose-sweetened food pellet reinforcement (45 mg; BioServ). Once responding stabilized, rats were fed ad libitum and trained to self-administer cocaine $(0.5 \mathrm{mg} / \mathrm{kg} / \mathrm{inf})$ or provided access to saline by pressing a lever during $2 \mathrm{~h}$ sessions. During these sessions, the active lever was extended into the chamber and the light above the active lever was illuminated. Infusions $(200 \mu \mathrm{l})$ were delivered intravenously over $5 \mathrm{~s}$ through delivery lines attached to syringes mounted in the automated pumps and were followed by a $5 \mathrm{~s}$ timeout phase during which the light above the active lever was extinguished but the lever remained extended. Responding during the timeout phase was not reinforced but was recorded. Responding on a second (inactive) lever was also recorded but had no consequences. Rats were initially trained under a fixed-ratio (FR) 1 schedule, the response requirement were gradually increased to FR4. Once stable self-administration was observed under the FR4 schedule (infusion numbers within $10 \%$ of a 3 -session mean), testing began. Depending on the experiment, rats were tested under the following conditions over the 14-d testing phase: (1) cocaine self-administration (0.5 $\mathrm{mg} / \mathrm{kg} / \mathrm{inf}$ ) during daily $2 \mathrm{~h}$ sessions (short-access; ShA rats), (2) cocaine self-administration $(0.5 \mathrm{mg} / \mathrm{kg} / \mathrm{inf})$ during daily $6 \mathrm{~h}$ sessions (long-access; LgA rats), and (3) saline self-administration during daily $2 \mathrm{~h}$ sessions (saline control; Sal rats). 
Following self-administration testing, rats underwent extinction training during daily $2 \mathrm{~h}$ sessions in which the cocaine solution was replaced with saline (saline control rats continued to have access to saline) but the experimental conditions were otherwise identical to those during self-administration. With the exception of Experiment 6, which used a set number of extinction sessions (10), daily extinction training continued in each rat until the extinction criterion was met $(<15$ active lever responses in two consecutive sessions). Following extinction training, rats were tested for shock-induced reinstatement of cocaine seeking and/or were killed and their brains processed for immunohistochemistry or in situ hybridization.

Shock-induced reinstatement. Stress-induced drug seeking was assessed using shock-induced reinstatement of extinguished lever pressing. The $2 \mathrm{~h}$ reinstatement sessions were identical to the extinction sessions except that they were preceded by the delivery of intermittent mild non-noxious footshock. In some cases, footshock administration was preceded by intracranial drug infusions. Shocks $(0.5 \mathrm{~mA}, 0.5 \mathrm{~s}$ duration) were delivered on average every $40 \mathrm{~s}$ (range 10-70 s) throughout the stainless-steel grid floors of the self-administration chambers over a 15 min period that was followed immediately by the $2 \mathrm{~h}$ reinstatement test session (Blacktop et al., 2011; Vranjkovic et al., 2014). During the shock period, the levers were not extended and neither the house light nor the light above the active lever were illuminated. Following cessation of the footshock, the levers were extended into the chamber and the lights illuminated. Reinstatement was defined as an increase in active lever responding during the reinstatement test relative to non-shock control conditions. Additionally, responding on a second, inactive, lever was recorded during the experimental sessions, but had no programmed consequences.

Experiment 1: relationship between prefrontal cortical Fos immunoreactivity and shock-induced reinstatement of cocaine seeking. We previously reported that robust shock-induced reinstatement of extinguished cocaine seeking is observed following daily $\operatorname{LgA}(14 \times 6 \mathrm{~h})$ but not ShA $(14 \times 2 \mathrm{~h})$ to cocaine for self-administration (Mantsch et al., 2008). To examine the relationship between shock-induced cocaine seeking and activation of the prelimbic and infralimbic regions of the medial prefrontal cortex, separate groups of rats underwent $14 \mathrm{~d}$ of self-administration under ShA or LgA cocaine or saline control conditions followed by daily extinction training, which continued until the extinction criterion was met. Saline control animals continued to have saline access for a period of time (10-14 d) that matched the duration of extinction in the ShA and LgA cocaine rats. Following extinction, rats were tested for reinstatement in response to shock (ShA rats, $n=6$; LgA rats, $n=10$; Sal rats, $n=7$ ) or under shock-free conditions (ShA rats, $n=7$; LgA rats, $n=7$; Sal rats, $n=6)$ and, immediately after the $2 \mathrm{~h}$ reinstatement session, were anesthetized with sodium pentobarbital $(55 \mathrm{mg} / \mathrm{kg}$, i.p.) and perfused transcardially with $0.1 \mathrm{M}$ PBS, followed by $\left(4^{\circ} \mathrm{C}\right) 4 \%$ paraformaldehyde in 0.1 $\mathrm{M}$ phosphate buffer, $\mathrm{pH}$ 7.0. Brains were removed and postfixed in $4 \%$ paraformaldehyde overnight at $4^{\circ} \mathrm{C}$ before washing in $0.1 \mathrm{M}$ sodium phosphate buffer and placement in $30 \%$ sucrose in $0.1 \mathrm{M}$ phosphate buffer for $3 \mathrm{~d}$. Frozen brains were sectioned $(30 \mu \mathrm{m})$ and coronal sections were taken from +3.24 to $+2.54 \mathrm{~mm}$ referenced to bregma. Sections were stored at $-20^{\circ} \mathrm{C}$ in before immunohistochemical analysis of Fos expression using an avidin-biotin peroxidase protocol (Hoffman et al., 2016). Fos immunolocalization was visualized using a primary polyclonal rabbit anti-Fos antibody (sc-52, Santa Cruz Biotechnology; RRID: AB_2106783; 1:10,000). Sections were washed in KPBS $(0.05 \mathrm{M})$ and incubated in $2 \%$ hydrogen peroxide in KPBS containing $0.4 \%$ Triton for $15 \mathrm{~min}$. Sections were washed again and then incubated in 3\% normal donkey serum for $1 \mathrm{~h}$ and then were incubated in the primary antibody containing $0.4 \%$ Triton $\mathrm{X}-100$ for $24 \mathrm{~h}$ at $4^{\circ} \mathrm{C}$. Next, sections were washed and incubated for $1 \mathrm{~h}$ in biotinylated horse anti-rabbit IgG secondary antibody (PI-1000, Vector Laboratories; RRID:AB_2336198; 1:600) before additional washing and $1 \mathrm{~h}$ incubation in $\mathrm{ABC}$ solution (PK-4000; Vector Laboratories; RRID:AB_2336818; 1:200). After another series of washes, sections were incubated in $0.175 \mathrm{~m}$ sodium acetate, $\mathrm{pH} 7.0$, and then treated with a nickel-enhanced diaminobenzidine method (blacknuclear reaction) (SK-4100, Vector Laboratories; RRID:AB_2336382) before another incubation in $0.175 \mathrm{M}$ sodium acetate and then washing in KPBS. Sections were mounted on Superfrost slides and dehydrated and coverslipped the next day. Fos immunoreactivity was quantified using ImageJ software (RRID:SCR_003070). The total numbers of Fos-positive cells within each cortical region (i.e., the sum across regions of all sections) were determined for each animal, corrected based on area of measurement $\left(\mathrm{mm}^{2}\right)$, and compared across groups.

Experiment 2: relationship between Fos immunoreactivity in VTA neurons that project to the prelimbic cortex and shock-induced reinstatement of cocaine seeking. To determine whether activation of VTA neurons that project to the prelimbic cortex is associated with stress-induced cocaine seeking, we used a retrograde tracer labeling approach. Rats underwent LgA self-administration followed by bilateral intra-prelimbic cortical infusions of the retrograde tracer cholera toxin subunit $\mathrm{b}(\mathrm{CTb})$. Rats were anesthetized with ketamine/xylazine and guide cannula (26-gauge) were positioned above the prelimbic cortex [coordinates, $\mathrm{mm}$ : anteroposterior $(\mathrm{A} / \mathrm{P})$ : +2.8 from bregma; mediolateral $(\mathrm{M} / \mathrm{L})$ : +1.0 from midline; dorsoventral (D/V): -2.0 ; Paxinos and Watson, 2013]. CTb (10\%; List Biological Laboratories, 104) was back-filled into micro-injectors (30gauge; Plastics One) attached to PE-20 tubing and connected to Hamilton syringes in an infusion pump. The injectors were lowered into the guide cannula and extended $2 \mathrm{~mm}$ beyond the guide cannula and $0.3 \mu \mathrm{l}$ of $\mathrm{CTb}$ was infused bilaterally into the prelimbic cortex over a $3 \mathrm{~min}$ period. Syringes were left in place for an additional $10 \mathrm{~min}$ after injections and slowly removed from the brain at a rate of $0.1 \mathrm{~mm} / \mathrm{min}$ for the first $\mathrm{mm}$. Following injections, rats recovered for at least $5 \mathrm{~d}$ before undergoing daily extinction training. Following $10 \mathrm{~d}$ of extinction, rats were tested for cocaine seeking in response to shock $(n=6)$ or under shock-free conditions $(n=5)$. Immediately following the $2 \mathrm{~h}$ reinstatement session, rats were killed and brains were processed for CTb/Fos labeling of VTA neurons using dual immunohistochemistry. For visualization purposes, we modified our immunohistochemistry protocol. Brains were sectioned on a cryostat at $25 \mu \mathrm{m}$ sections from -5.2 to -5.8 $\mathrm{mm}$ from bregma. Analysis of Fos expression was performed on freefloating sections using an avidin-biotin peroxidase-based reaction. Fos immunolocalization was visualized using the primary polyclonal rabbit anti-Fos antibody (ABE457, Millipore; RRID:AB_2631318; 1:30,000). Sections were washed in KPBS $(0.05 \mathrm{M})$ and incubated in 3\% hydrogen peroxide in KPBS for 30 min and then washed in KPBS with $0.1 \%$ Triton $\mathrm{X}-100$ (KPBST) and incubated in 5\% natural horse serum in KPBST for $1 \mathrm{~h}$ at $22^{\circ} \mathrm{C}$. Sections were then incubated in Fos primary antibody in KPBST overnight at room temperature, washed, and incubated for 90 min in biotinylated horse anti-rabbit IgG secondary antibody (PI-1000, Vector Laboratories; RRID: AB_2336198; 1:600). Sections were then washed again and incubated for $1 \mathrm{~h}$ in ABC solution made in KPBST (PK-4000, Vector Laboratories; RRID:AB_2336818; 1:200). After additional washes in KPBST and KPBS, sections were washed in $0.175 \mathrm{M}$ sodium acetate, $7.0 \mathrm{pH}$. Sections were then treated with a nickelenhanced diaminobenzidine (NiDAB) method for 20 min (blacknuclear reaction; SK-4100, Vector Laboratories; RRID:AB_2336382). After the NiDAB reaction, $\mathrm{CTb}$ was visualized using the same steps above with the following modifications: (1) the hydrogen peroxide step was reduced to $2 \%$ hydrogen peroxide and was $15 \mathrm{~min}$. (2) The secondary used was a biotinylated horse anti-goat IgG antibody (BA-9500, Vector Laboratories; RRID:AB_2336123; 1:600) made in 0.3\% KPBST for 60 min. (3) The addition of an avidin-biotin blocking step (SP-2100, Vector Laboratories) before incubation with the goat anti-CTb primary antibody (703, List Biology; RRID:AB_10013220; 1:40,000). Sections were incubated in $\mathrm{CTb}$ antibody overnight at $4^{\circ} \mathrm{C}$ and, thereafter, in a biotinylated horse anti-goat IgG secondary antibody in 0.3\% KPBST for 60 min. Sections were washed and incubated for $1 \mathrm{~h}$ in $\mathrm{ABC}$ solution and then washed again before treatment using the DAB method (light brown cytoplasmic staining) for visualization of $\mathrm{CTb}$. After additional washing, sections were slide-mounted and coverslipped. Photomicrographs were acquired using an AxioCam Color camera using an Axioskop 2 microscope (Carl Zeiss) with AxioVision Rel. 4.6 software (ZEISS; RRID: SCR_002677). Fos ${ }^{+}$(black nuclear stain with no surrounding light brown cytosolic stain), $\mathrm{CTb}^{+}$(light brown cytosolic stain with no nuclear stain), and dual Fos ${ }^{+} / \mathrm{CTb}^{+}$cells (darker brain nuclear stain with surrounding light brown cytosolic stain) were identified and counted using ImageJ software by averaging both hemispheres from -5.2 to 
$-5.8 \mathrm{~mm}$ for each brain then correcting based on area of measurement $\left(\mathrm{mm}^{2}\right)$. Using a similar approach, it has been reported that restraint stress selectively increases Fos expression in VTA neurons that project to the prelimbic cortex in rats (Deutch et al., 1991).

Experiment 3: Effects of chemogenetic inhibition of

VTA neurons that project to the prelimbic cortex on

shock-induced cocaine seeking. A dual-virus intersectional hM4Di DREADD (designer receptor exclusive activated by design drug) based approach was used to test the necessity of VTA neurons that project to the prelimbic cortex for shock-induced cocaine seeking. At the time of catheter implantation, nine rats received bilateral injections of a Crerecombinase-expressing canine adenovirus (CAV2-Cre; Institute of Molecular Genetics, Montpellier, France) into the prelimbic cortex and bilateral injections of AAV5 expressing a double-floxed Gi-coupled hM4Di DREADD fused with mCherry under the control of human synapsin promoter (pAAV-hSyn-DIO-hM4Di-mCherry; Duke University Viral Vector Core) into the VTA to produce isolated hM4Di expression in VTA neurons that project to the prelimbic cortex. Twenty-six gauge cannulae were placed $2 \mathrm{~mm}$ above the prelimbic cortex ( $8^{\circ}$ angle: A/P: $+2.5 \mathrm{~mm} ; \mathrm{M} / \mathrm{L}:+1.0 \mathrm{~mm} ; \mathrm{D} / \mathrm{V}:-2.0 \mathrm{~mm})$ or the VTA $\left(0^{\circ}\right.$ angle; $\mathrm{A} / \mathrm{P}$ : $-5.6 \mathrm{~mm}$; M/L: $-0.75 \mathrm{~mm}$; D/V; $-6.20 \mathrm{~mm}$ ) for insertion of a 30 -gauge microinjector that extended $2 \mathrm{~mm}$ below the cannula termination point to permit micro-infusion of virus at a rate of $0.1 \mu \mathrm{l} / \mathrm{min}$ for a total volume of $0.5 \mu \mathrm{l}$. For the VTA, after the initial infusion, the injectors were raised to a $\mathrm{D} / \mathrm{V}$ coordinate of $-5.0 \mathrm{~mm}$ so that a second infusion (also $0.5 \mu \mathrm{l}$ ) could be delivered into the dorsal aspects of the region. Injectors were left in place for $10 \mathrm{~min}$ to permit diffusion and then raised at a rate of 1 $\mathrm{mm} / \mathrm{min}$. A second group of eight rats that received only the pAAVhSyn-DIO-hM4Di-mCherry injections in the VTA served a control for potential Cre-independent hM4Di expression and/or DREADDindependent effects of CNO.

Following surgery, rats were allowed to recover for 5-6 d before selfadministration training, as described above. Once trained, rats underwent $14 \mathrm{~d}$ of self-administration under daily $\operatorname{LgA}(6 \mathrm{~h})$ conditions before extinction training, which continued until the extinction criterion was met ( $<15$ previously active lever responses in two consecutive sessions) at which point reinstatement testing was conducted. During separate reinstatement test sessions rats were tested for cocaine seeking in response to electric footshock or a priming injection of cocaine $(10 \mathrm{mg} / \mathrm{kg}$, i.p.) $30 \mathrm{~min}$ following pretreatment with vehicle (5\% DMSO in saline) or one of two doses of the DREADD agonist, CNO (1 or $2 \mathrm{mg} / \mathrm{kg}$, i.p.). Reinstatement sessions were separated by at least one extinction session during which $<15$ previously active lever responses were observed. Following the completion of testing, rats were perfused and their brains were processed for confirmation of prelimbic and VTA injection sites and VTA mCherry expression using an immunofluorescence-based approach. Sections $(25 \mu \mathrm{m})$ were placed in a $0.05 \mathrm{M}$ PBS solution containing $0.3 \%$ Triton X-100 for $1 \mathrm{~h}$ and then in a blocking solution ( $1 \%$ bovine serum albumin, $5 \%$ normal donkey serum, $0.1 \%$ Triton $\mathrm{X}-100,0.3 \mathrm{M}$ glycine; in $0.05 \mathrm{M}$ PBS) for $3 \mathrm{~h}$ at $22^{\circ} \mathrm{C}$ before exposure to the mCherry primary antibody (1:1000; Clontech Laboratories; RRID: AB_10013483) solution (1\% BSA, $5 \%$ normal donkey serum, $0.1 \%$ Triton X-100; made in $0.05 \mathrm{M}$ PBS) for $36 \mathrm{~h}$ at $4^{\circ} \mathrm{C}$ and then incubation in secondary donkey anti-rabbit AlexaFluor 594 antibody (1:250; Invitrogen; RRID: $\left.\mathrm{AB} \_141637\right)$ in $0.05 \mathrm{M}$ PBS with $0.1 \%$ Triton $\mathrm{X}-100$ for $2 \mathrm{~h}$ at $22^{\circ} \mathrm{C}$. Sections were then mounted and imaged on a Nikon A1R confocal microscope (Nikon Instruments) and analyzed using NIS ElementsAdvanced Research (Nikon Instruments). Rats with no mCherry expression or mCherry expression outside of the VTA were excluded from the behavioral analyses. Expression of mCherry in tyrosine hydroxylase (TH)-positive neurons in the VTA was determined in five rats. Colocalization was determined using the above protocol, with the addition of a TH primary antibody (1:2500; Millipore; RRID: AB_2201528) included at the $36 \mathrm{~h}$ incubation stage, and the additional secondary donkey anti-mouse AlexaFluor 488 (1:250; Invitrogen; RRID: AB_141607) at the secondary incubation step.

Experiment 4: role of VTA CRFR1 in shock-induced cocaine seeking and cortical subregion activation. To test for the contribution of VTA CRFR1 to the cortical Fos response associated with shock-induced cocaine seek- ing, rats were implanted with jugular catheters followed by implantation of bilateral guide cannula (11 mm, 26-gauge) aimed at the VTA [coordinates (in $\mathrm{mm}$ ): $\mathrm{A} / \mathrm{P}:-5.6$ from bregma; $\mathrm{M} / \mathrm{L}$ : +2.2 from midline; $\mathrm{D} / \mathrm{V}$ : -6.9 from the skull surface; Paxinos and Watson, 2013] and underwent cocaine self-administration under LgA conditions and extinction before testing for reinstatement in response to shock or under shock-free conditions. Before the $2 \mathrm{~h}$ reinstatement session, rats received bilateral intraVTA infusions of the CRFR1 receptor antagonist, antalarmin $(500 \mathrm{ng} /$ side) or vehicle ( $n=5$ per group). We (Blacktop et al., 2011; Vranjkovic et al., 2014) and others (Lowery-Gionta et al., 2012) have used this antalarmin dose to investigate CRFR1-dependent contributions to behavior. Micro-infusions were administered $10 \mathrm{~min}$ before the shock or shockfree period and were delivered through a microinjector (30-gauge) that extended $0.5 \mathrm{~mm}$ beyond the guide cannula and was attached to polyethylene (PE-20) tubing connected to Hamilton syringes in an infusion pump. The infusions were given at a volume of $0.25 \mu \mathrm{l} /$ side over a $1 \mathrm{~min}$ period followed by an additional $1 \mathrm{~min}$ period to allow for drug diffusion. Immediately after the $2 \mathrm{~h}$ session, rats were then killed and brains were processed (as described for Experiment 1) for immunohistochemical analysis of Fos expression in the prelimbic and infralimbic cortices. Guide cannula placements were verified postmortem following staining of sections containing VTA with cresyl violet and confirmation of needle track termination in the VTA using a light microscope. Rats with injection sites outside of the VTA were excluded from data analysis.

Experiment 5: effect of pharmacological disconnection of the CRFregulated dopaminergic pathway from the VTA to the prelimbic cortex on shock-induced cocaine seeking. An asymmetric pharmacological disconnection approach was used to determine whether a CRFR1-activated dopaminergic projection from the VTA to the prelimbic cortex is required for stress-induced cocaine seeking. The utility of this approach assumes that the neural pathways under investigation are primarily lateralized (Gold, 1966). Accordingly, it has been reported that $96 \%$ of VTA neurons projecting to the prelimbic cortex are ipsilateral (Hosp et al., 2015). At the time of catheterization, separate groups of rats were implanted with two cannula aimed unilaterally at the VTA (A/P $-5.6 \mathrm{~mm}$; $\mathrm{M} / \mathrm{L}:+2.2 \mathrm{~mm}$; D/V: $-6.9 \mathrm{~mm})$ or prelimbic cortex $(\mathrm{A} / \mathrm{P}+2.8 \mathrm{~mm}$; $\mathrm{M} / \mathrm{L}+1.0 \mathrm{~mm}$; D/V $-3.5 \mathrm{~mm}$ ) in either the contralateral or ipsilateral hemisphere(s) of the brain. The effect of pathway disconnection was examined by injection of the CRFR1 receptor antagonist, antalarmin (500 ng), into the VTA in one hemisphere and the dopamine D1 receptor antagonist SCH23390 (200 ng) into the prelimbic cortex of the other 15 min before testing for shock-induced reinstatement $(n=7)$. For comparison, the same rats were tested for shock-induced reinstatement following injection of vehicle into each region. As a control to ensure that reductions in reinstatement were attributable to disconnection, a second group of rats $(n=7)$ received a unilateral injection of antalarmin into the VTA in one hemisphere and a unilateral injection of SCH23390 into the prelimbic cortex in the same hemisphere before testing for shockinduced reinstatement. These rats were also tested for the effects of ipsilateral vehicle injections. For this experiment, the hemispheres into which cannula were implanted were randomized across rats in each group such that in the contralateral treatment group, half of the rats received antalarmin injections into the left VTA and SCH23390 injections into the right prelimbic cortex, whereas the other half received antalarmin injections into the right VTA and SCH23390 injections into the left prelimbic cortex. Likewise, half of the rats in the ipsilateral treatment group received drug injections into sites in the right hemisphere, while the remaining rats received injections into sites in the left hemisphere. A third group of rats $(n=5)$ was implanted with cannula for disconnection of CRFR1-regulated VTA dopaminergic inputs into the infralimbic cortex $(\mathrm{A} / \mathrm{P}+2.8 \mathrm{~mm} ; \mathrm{M} / \mathrm{L}+1.0 \mathrm{~mm} ; \mathrm{D} / \mathrm{V}-4.0 \mathrm{~mm})$. As with the prelimbic cortex disconnection experiment, these rats received an antalarmin injection into the VTA of one hemisphere and a SCH23390 injection into the infralimbic cortex of the other. The accuracy of cannula implantation was confirmed postmortem as described in Experiment 4. Rats with injection sites outside of the targeted regions were excluded from data analysis.

Experiment 6: effects of cocaine self-administration under conditions that promote shock-induced cocaine seeking on CRFR1 mRNA in the VTA. We 
previously reported that intra-VTA CRF injections reinstate cocaine seeking in rats with a history of $\operatorname{LgA}$, but not ShA, self-administration (Blacktop et al., 2011). To determine whether LgA self-administration regulates VTA CRFR1 mRNA, we used in situ hybridization to examine differences in the expression of CRFR1 mRNA within the VTA after self-administration under ShA $(n=8), \operatorname{LgA}(n=8)$, and saline control $(n=8)$ conditions. All rats were tested under their respective conditions and underwent extinction. For this experiment, all rats underwent extinction training for 10 consecutive days (in contrast to the other experiments, which applied an extinction criterion before reinstatement testing/processing). Twenty-four hours after the final extinction session, brains were removed following rapid decapitation in the absence of anesthesia and were placed in 2-methylbutane for $1 \mathrm{~min}$ at $-30^{\circ} \mathrm{C}$ before storage at $80^{\circ} \mathrm{C}$ until sectioning. The tissue was sectioned on a cryostat to $14 \mu \mathrm{m}$ thickness and placed onto Superfrost Plus slides (Fisher Scientific) and stored in a $-80^{\circ} \mathrm{C}$ freezer. Sections were collected in series of six slides ( 4 sections/slide); every sixth slide was stained with cresyl violet to determine anatomical location. A $1138 \mathrm{bp}$ fragment of the rat CRFR1 cDNA (NCBI NM_030999, nucleotides 99-1236) was isolated by PCR from rat cortex $\mathrm{CDNA}$ and subcloned into PCRII-TOPO (Invitrogen) to create pCRII-TOPO-rCRFR1-1. For antisense riboprobe synthesis, the pCRII-TOPO-rCRFR1-1 plasmid was linearized with BamHI and transcribed with T7 RNA polymerase (Promega). The riboprobe was doublelabeled with ${ }^{35} \mathrm{~S}$-CTP and ${ }^{35} \mathrm{~S}$-UTP (PerkinElmer; $1250 \mathrm{Ci} / \mathrm{mmol}$ ) and free nucleotides were removed using a Micro Bio-Spin column (BioRad). In situ hybridization was performed as previously described with minimal modifications (Speert et al., 2002; Westphal et al., 2009). Briefly, slides were postfixed for $1 \mathrm{~h}$ in $4 \%$ phosphate-buffered paraformaldehyde and washed in saline-sodium citrate (SSC) buffer. Sections were incubated in $0.1 \mathrm{~m}$ triethanolamine containing $0.25 \%$ acetic anhydride for 10 min with stirring, rinsed in $\mathrm{dH}_{2} \mathrm{O}$, dehydrated and air-dried. Slides were then hybridized overnight at $55^{\circ} \mathrm{C}$ with the ${ }^{35}$ S-labeled CRFR1 riboprobe $\left(2 \times 10^{6} \mathrm{cpm} / \mathrm{slide}\right)$ in $50 \%$ formamide hybridization mixture (AMRESCO) containing 20 mm DTT. After hybridization, excess unhybridized probe was removed with three $2 \times$ SSC washes and by incubating slides in RNase A $\left(200 \mu \mathrm{g} / \mathrm{ml}, 37^{\circ} \mathrm{C}, 1 \mathrm{~h}\right)$. Slides were then washed at $\mathrm{RT}$ in decreasing salt solutions $(2 \times, 1 \times$, and $0.5 \times$ SSC) before a final high-stringency wash in $0.1 \times \operatorname{SSC}\left(65^{\circ} \mathrm{C}, 1 \mathrm{~h}\right)$. Slides were then dehydrated in ethanol, air-dried, and apposed to Kodak BioMax MR autoradiography film (Carestream) for $7 \mathrm{~d}$. Four to five slides (1/series) from each rat (16-20 sections spanning $\sim 1.2 \mathrm{~mm}$ across VTA) were included and were processed simultaneously to allow direct comparisons in the same regions and minimize variation. Autoradiography films were scanned and analyzed using densitometry in ImageJ v1.48g5. Two macros were used that enabled background to be selected and a mask created so that only signal $>3.5 \mathrm{SD}$ above background was measured (background was determined on each tissue section). Mean optical density $(\mathrm{OD})$, area of signal, and integrated optical density (IOD; mean OD $\times$ area of signal) were determined for VTA from left and right hemispheres. The CRFR1 mRNA signal (IOD) from multiple VTA sections (spanning bregma -5.2 to -6.0 ) was determined and averaged to generate one single integrated OD per region per rat. This anatomical region was selected based on (1) our observation that CRF delivery to the VTA at $-5.6 \mathrm{~mm}$ bregma reinstates cocaine seeking in a manner that increases with long-access self-administration (Blacktop et al., 2011), (2) our finding that CRFR1 antagonist injections at the $-5.6 \mathrm{~mm}$ bregma prevents shock-induced cocaine seeking, and (3) the observation in this study that shock-induced cocaine seeking is associated with Fos expression in this region of the VTA.

Experimental design and statistical analysis. Statistical analyses were conducted using IBM SPSS Statistics software v24. For Experiment 1, a between-subjects design was used. Effects on cocaine seeking and Fos were assessed using two-way ANOVA, followed, when appropriate by post hoc testing using Bonferroni-corrected $t$ tests. For Experiment 2, comparisons were made between two groups and unpaired $t$ tests were used to assess effects on cocaine seeking and Fos. For Experiment 3, a within-subjects design was used. Effects on cocaine seeking were assessed using two-way repeated-measures ANOVA, followed, when appropriate by post hoc testing using Bonferroni-corrected $t$ tests. For Experiment 4, a between-subjects design was used. Effects on cocaine seeking and Fos were assessed using two-way ANOVA, followed, when appropriate by post hoc testing using Bonferroni-corrected $t$ tests. For Experiment 5, a within-subjects design was used. Effects on cocaine seeking were assessed using two-way repeated-measures ANOVA, followed, when appropriate by post hoc testing using Bonferroni-corrected $t$ tests. For Experiment 6, a between-subjects design was used. Effects on CRF mRNA were assessed using one-way ANOVA, followed, when appropriate by post hoc testing using Bonferroni-corrected $t$ tests.

\section{Results}

\section{Cocaine self-administration and extinction}

Rats acquired stable self-administration in an overall mean of $10.3 \mathrm{~d}$ (range 3-23). Self-administration data for each experiment (infusions on Days 1 and 14 of self-administration testing and total $\mathrm{mg} / \mathrm{kg}$ cocaine intake across all sessions) are shown in Table 1 and in Figures 1-1 (available at https://doi.org/10.1523/ JNEUROSCI.2080-18.2018.f1-1); Figures 2-1 (available at https:// doi.org/10.1523/JNEUROSCI.2080-18.2018.f2-1); Figures 3-1 (available at https://doi.org/10.1523/JNEUROSCI.2080-18.2018. f3-1); Figures 4-1 (available at https://doi.org/10.1523/JNEUROSCI. 2080-18.2018.f4-1); Figures 5-1 (available at https://doi.org/10. 1523/JNEUROSCI.2080-18.2018.f5-1); Figures 6-1 (available at https://doi.org/10.1523/JNEUROSCI.2080-18.2018.f6-1). Extinction data (responses during the first and final $2 \mathrm{~h}$ session before reinstatement testing and number of days before meeting) for each experiment are shown in Table 1.

\section{Experiment 1: relationship between prefrontal cortical Fos immunoreactivity and shock-induced reinstatement of cocaine seeking}

Rats underwent daily cocaine self-administration for $14 \mathrm{~d}$ under ShA $(2 \mathrm{~h} / \mathrm{d})$ or $\operatorname{LgA}(6 \mathrm{~h} / \mathrm{d})$ conditions or were provided access to saline for self-administration, before undergoing extinction, after which they were tested for cocaine seeking under shock-free conditions or following shock exposure and their brains were processed for cortical Fos analysis. Shock-induced cocaine seeking is shown in Figure 1A. Similar to previous reports (Mantsch et al., 2008), robust shock-induced reinstatement was observed in rats following LgA cocaine self-administration but not following ShA self-administration, and shock did not increase lever pressing in control rats provided access to saline. A two-way selfadministration condition (ShA, LgA, vs Sal) $\times$ shock condition (shock vs no shock) ANOVA examining effects on cocaine seeking showed a significant interaction $\left(F_{(2,38)}=9.38 ; p<0.001\right)$. Post hoc testing showed that shock-induced cocaine seeking, as defined by increased lever pressing relative to the non-shock control, was only observed following long-access/high-intake selfadministration $(p=0.011)$. Moreover, cocaine seeking following shock was significantly higher following LgA self-administration than it was after ShA self-administration $(p=0.015)$ or in saline controls $(p=0.041)$. Effects on responding on the previously inactive lever were not observed (Fig. $1 B$; two-way shock $\times$ selfadministration condition ANOVA; no main effect of condition: $F_{(2,38)}=0.65$, or shock: $F_{(1,38)}=1.85$, and no interaction: $F_{(2,38)}=$ $0.17 ; p>0.05)$.

Fos data are reported as the number of Fos-positive cells per $\mathrm{mm}^{2}$ in the prelimbic and infralimbic cortex following behavioral testing under shock and shock-free conditions were recorded in each group and are shown in Figure 1, $C$ (prelimbic cortex) and $D$ (infralimbic cortex). Figure $1 E$ and $F$, represent schematics identifying the regions in which Fos immunoreactivity was analyzed (Paxinos and Watson, 2013). Representative immunolabeled sections including the cortical regions of interest 
Table 1. Cocaine SA and extinction (Ext) data

\begin{tabular}{|c|c|c|c|c|c|c|c|c|}
\hline Experiment & Group & $n$ & $\begin{array}{l}\text { SA Day 1, } \\
\text { infusions } \pm \text { SE }\end{array}$ & $\begin{array}{l}\text { SA Day 14, } \\
\text { infusions } \pm \text { SE }\end{array}$ & $\begin{array}{l}\text { Total intake, } \\
\text { net } \mathrm{mg} / \mathrm{kg} \pm \mathrm{SE}\end{array}$ & $\begin{array}{l}\text { First Ext, } \\
\text { responses } \pm S E\end{array}$ & $\begin{array}{l}\text { Last Ext, } \\
\text { responses } \pm \text { SE }\end{array}$ & $\begin{array}{l}\text { Days to } \\
\text { Ext } \pm \text { SE }\end{array}$ \\
\hline \multirow[t]{6}{*}{1} & Sal/No Shock & 9 & $5.2 \pm 1.2$ & $1.5 \pm 0.2$ & 0 & $5.4 \pm 1.0$ & $5.0 \pm 1.0$ & $11.1 \pm 0.6$ \\
\hline & Sal/Shock & 9 & $3.7 \pm 0.9$ & $2.4 \pm 0.6$ & 0 & $5.0 \pm 1.9$ & $4.8 \pm 0.8$ & $11.9 \pm 1.3$ \\
\hline & ShA/No Shock & 7 & $24.0 \pm 3.2$ & $21.6 \pm 4.8$ & $71.0 \pm 4.0$ & $73.8 \pm 15.2$ & $9.4 \pm 2.8$ & $12.8 \pm 0.9$ \\
\hline & Sha/Shock & 6 & $26.6 \pm 1.3$ & $21.4 \pm 5.1$ & $67.4 \pm 3.6$ & $45.2 \pm 13.8$ & $5.1 \pm 1.4$ & $10.8 \pm 0.2$ \\
\hline & LgA/No Shock & 6 & $82.1 \pm 3.9$ & $96.9 \pm 2.3$ & $243.7 \pm 6.2$ & $36.0 \pm 11.0$ & $11.7 \pm 2.3$ & $14.0 \pm 1.5$ \\
\hline & LgA/Shock & 10 & $77.7 \pm 4.2$ & $90.9 \pm 6.2$ & $225.6 \pm 13.9$ & $42.7 \pm 11.9$ & $11.5 \pm 3.0$ & $13.2 \pm 1.3$ \\
\hline \multirow[t]{2}{*}{2} & No Shock & 5 & $63.5 \pm 15.2$ & $91.2 \pm 0.9$ & $210.3 \pm 14.2$ & $45.8 \pm 12.8$ & $7.0 \pm 5.3$ & $10.4 \pm 1.4$ \\
\hline & Shock & 6 & $71.5 \pm 7.3$ & $88.0 \pm 4.3$ & $218.4 \pm 26.3$ & $34.8 \pm 7.5$ & $10.0 \pm 2.0$ & $9.5 \pm 2.1$ \\
\hline \multirow[t]{2}{*}{3} & $\mathrm{hM} 4 \mathrm{Di}$ & 7 & $64.0 \pm 5.1$ & $78.0 \pm 8.7$ & $202.8 \pm 9.2$ & $32.2 \pm 3.5$ & $11.3 \pm 1.9$ & $18.0 \pm 5.2$ \\
\hline & Control & 6 & $71.5 \pm 4.0$ & $80.9 \pm 5.0$ & $209.3 \pm 8.0$ & $43.5 \pm 4.3$ & $9.0 \pm 2.0$ & $11.9 \pm 1.5$ \\
\hline \multirow[t]{4}{*}{4} & Veh/No Shock & 5 & $83.6 \pm 4.3$ & $91.6 \pm 6.3$ & $212.9 \pm 27.6$ & $67.3 \pm 18.3$ & $8.0 \pm 1.8$ & $8.5 \pm 0.5$ \\
\hline & Veh/Shock & 5 & $65.0 \pm 12.3$ & $94.0 \pm 4.9$ & $218.5 \pm 21.5$ & $54.5 \pm 14.3$ & $8.0 \pm 1.8$ & $6.3 \pm 0.8$ \\
\hline & Ant/No Shock & 5 & $78.0 \pm 9.0$ & $105.1 \pm 11.2$ & $233.0 \pm 37.5$ & $56.7 \pm 20.3$ & $6.8 \pm 2.4$ & $6.7 \pm 0.5$ \\
\hline & Ant/Shock & 5 & $80.6 \pm 4.6$ & $100.2 \pm 7.5$ & $222.1 \pm 25.3$ & $92.2 \pm 21.3$ & $8.0 \pm 2.8$ & $5.3 \pm 0.2$ \\
\hline \multirow[t]{3}{*}{5} & PL/VTA Contra & 7 & $61.9 \pm 8.3$ & $80.7 \pm 6.9$ & $179.8 \pm 11.8$ & $43.3 \pm 9.2$ & $6.7 \pm 1.6$ & $9.4 \pm 1.7$ \\
\hline & PL/VTA Ipsi & 7 & $62.9 \pm 8.9$ & $79.7 \pm 8.7$ & $199.9 \pm 13.0$ & $67.0 \pm 15.5$ & $10.7 \pm 1.6$ & $9.9 \pm 1.7$ \\
\hline & IL/VTA Contra & 5 & $73.0 \pm 6.2$ & $82.0 \pm 7.2$ & $209.6 \pm 20.3$ & $70.0 \pm 37.6$ & $8.8 \pm 2.3$ & $11.8 \pm 1.8$ \\
\hline \multirow[t]{3}{*}{6} & Sal & 8 & $3.6 \pm 0.8$ & $3.3 \pm 1.8$ & 0 & $4.5 \pm 1.3$ & $3.2 \pm 0.9$ & 10 \\
\hline & ShA & 8 & $28.7 \pm 2.6$ & $21.2 \pm 4.0$ & $70.0 \pm 7.7$ & $46.3 \pm 10.0$ & $26.7 \pm 7.7$ & 10 \\
\hline & $\operatorname{LgA}$ & 8 & $67.4 \pm 7.8$ & $85.10 .6 \pm 8.6$ & $211.1 \pm 13.3$ & $51.0 \pm 15.7$ & $20.2 \pm 6.6$ & 10 \\
\hline
\end{tabular}

Data represent cocaine SA by rats in each experiment, expressed as the numbers of infusions/session on Days 1 and 14 during the SA test period and total cocaine intake ( $\mathrm{mg} / \mathrm{kg}$ ) across the $14 \mathrm{~d}$ period, responding (lever presses) during the first and last extinction session prior to reinstatement testing and the number of sessions required to meet the extinction criterion for each experiment. All data represent mean $\pm S E$. The final sample size ( $n$ ) for each experiment is also listed. PL, Prelimbic cortex; IL, intralimbic cortex.
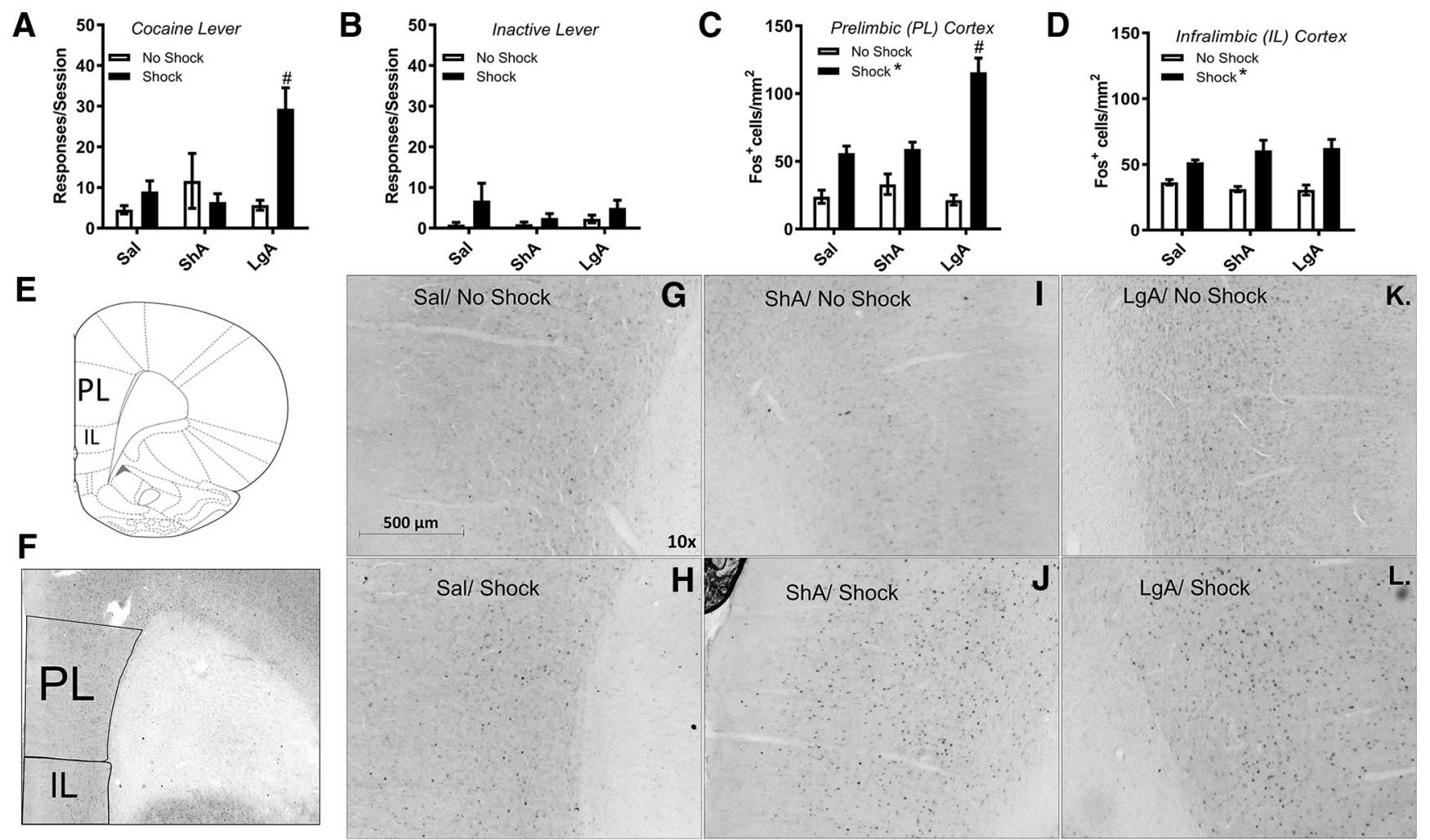

Figure 1. Stressor-induced cocaine seeking is associated with a heightened Fos response in the prelimbic cortex. Data in $\boldsymbol{A}$ and $\boldsymbol{B}$ represent responding (mean $\pm \mathrm{SE}$ ) on the cocaine $(\boldsymbol{A})$ and previously inactive $(B)$ levers during reinstatement testing following shock delivery or in the absence of shock in rats with a history of self-administration (SA) under ShA (0.5 mg/kg/infusion cocaine; $14 \times 2 \mathrm{~h} /$ daily; no shock, $n=5$; shock, $n=6), \mathrm{LgA}(0.5 \mathrm{mg} / \mathrm{kg} /$ infusion cocaine; $14 \times 6 \mathrm{~h} /$ daily; no shock, $n=6$; shock, $n=10)$, or Sal control $(14 \times 2 \mathrm{~h} /$ daily; no shock, $n=9 ;$ shock, $n=7)$ conditions. Shock only induced cocaine seeking following LgA SA ( $p=0.011$ vs No Shock controls with increased responding relative to Sal, $p=0.015$, and ShA, $p=0.041$ rats) and failed to alter inactive lever responding. Data in $\boldsymbol{C}$ and $\boldsymbol{D}$ represent the numbers of Fos-positive cells per square millimeter (mean \pm SE) in the prelimbic cortex $(\boldsymbol{C}$ ) and infralimbic cortex (D) following behavioral testing under shock and shock-free conditions. $\boldsymbol{E}, \boldsymbol{F}$, Schematics identifying the regions in which Fos immunoreactivity was analyzed. Representative immunolabeled sections including the cortical regions-of-interest ( +3.0 to $+2.5 \mathrm{~mm}$ relative to bregma) from each condition/group are shown in $\mathbf{G}-\boldsymbol{L}$. Shock increased in the number of Fos-positive cells in both regions (* ${ }^{*}$ overall effect of Shock; $p<0.001$ for each region). In the prelimbic cortex, but not the infralimbic cortex, this response was heightened following LgA self-administration relative to No Shock ( $\left.{ }^{\#} p<0.001\right)$, Sal ( $p=0.005$ ), and ShA $(p=0.002)$ rats. Corresponding extinction and self-administration data are depicted in Figure 1-1, available at https://doi.org/10.1523/JNEUROSCI.2080-18.2018.f1-1. All data represent mean \pm SE. 
A

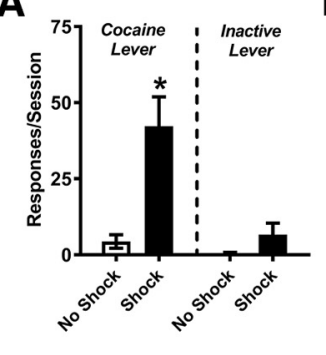

B

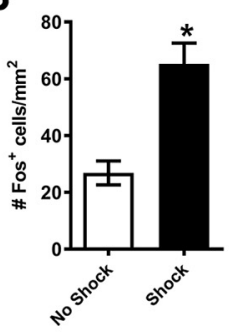

$\mathbf{F}$

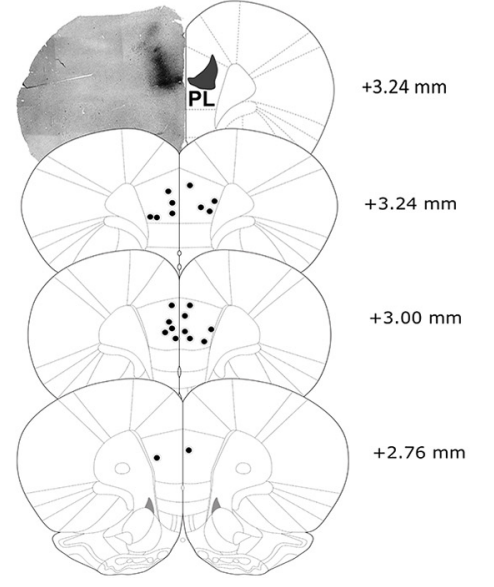

C

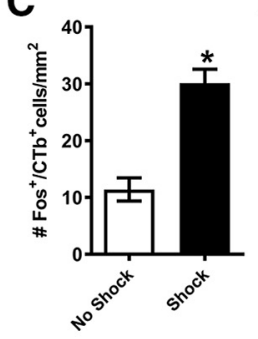

D

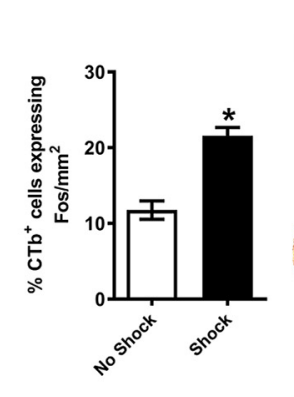

E

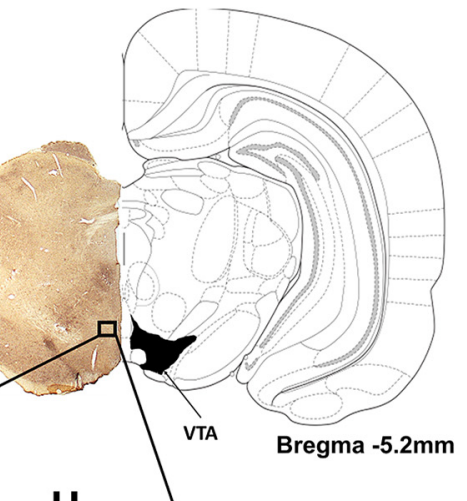

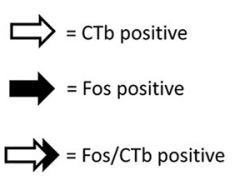

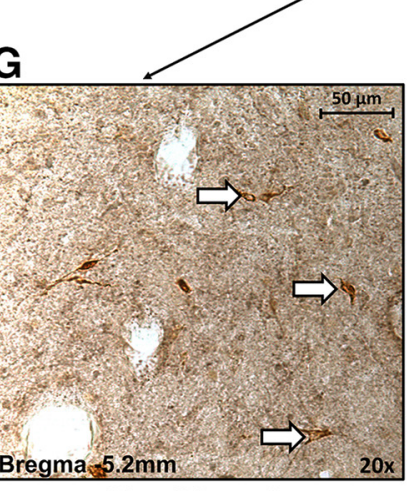

No Shock

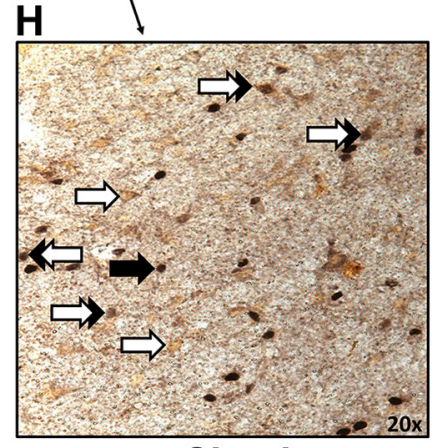

Shock

Figure 2. Stressor-induced cocaine seeking is associated with Fos expression in VTA neurons that project to the prelimbic cortex. To determine whether shock-induced cocaine seeking is associated with the activation of VTA neurons that project to the prelimbic cortex, CTb was injected bilaterally into the prelimbic cortex and Fos expression in CTb-labeled cells in the VTA was quantified. Cocaine seeking but not inactive lever responding was increased when rats received shock $\left({ }^{*} p<0.001\right.$, No Shock controls; $\left.\boldsymbol{A}\right)$. The total number of Fos-expressing cells $\left(\boldsymbol{B} ;{ }^{*} p=0.002\right)$, the total number of CTb-positive cells expressing Fos $\left(\boldsymbol{C} ;{ }^{*} p=0.042\right)$, and the percentage of CTb-labeled cells expressing Fos $\left(\boldsymbol{D} ;{ }^{*} p<0.001\right)$ in the VTA (per mm ${ }^{2}$ ) were increased in rats tested for shock-induced reinstatement relative to No Shock controls. The region of quantitation in the VTA is shown in $\boldsymbol{E}$. (Tb injection sites in the prelimbic cortex (PL) for rats included in the analyses are depicted in $\boldsymbol{F}$. Representative images containing VTA from each group are shown in $\boldsymbol{G}$ and $\boldsymbol{H}$. Examples of Fos-positive (black arrow), CTb-positive (white arrow), and CTb/Fos-positive (both arrows) are identified in the images. Corresponding extinction and self-administration data are depicted in Figure 2-1, available at https://doi.org/10.1523/JNEUROSCI.2080-18.2018.f2-1. All data represent mean \pm SE.

from each condition/group are shown in Figure $1 G-L$. A two-way shock $\times$ self-administration condition ANOVA showed a significant overall effect of shock $\left(F_{(1,39)}=51.08 ; p<0.001\right)$ and self-administration condition on the number of Fos-positive cells per square millimeter in the prelimbic cortex $\left(F_{(2,39)}=8.31 ; p=\right.$ $0.002)$ and a significant shock $\times$ self-administration condition interaction $\left(F_{(2,39)}=11.41 ; p<0.001\right)$. Post hoc testing showed that shock increased the number of Fos-positive cells per square millimeter in rats tested under each condition relative to nonshocked controls $(p=0.002$, saline; $p=0.015$, ShA; $p<0.001$, $\operatorname{LgA}$ ). This increase was significantly greater in rats tested under LgA conditions compared with either ShA $(p=0.002)$ or saline control ( $p=0.005)$ conditions. Shock also modestly but significantly increased the number of Fos-immunoreactive cells per $\mathrm{mm}^{2}$ in the infralimbic cortex (two-way ANOVA; overall effect of shock; $\left.F_{(1,39)}=28.08 ; p<0.001\right)$. However, no overall effect of self-administration condition $\left(F_{(2,39)}=0.11 ; p>0.05\right)$ or selfadministration condition $\times$ shock interaction $\left(F_{(2,39)}=1.16 ; p>\right.$ $0.05)$ was observed.

Experiment 2: relationship between Fos immunoreactivity in VTA neurons that project to the prelimbic cortex and shockinduced reinstatement of cocaine seeking

To determine whether shock-induced cocaine seeking was associated with activation of VTA neurons that project to the prelimbic cortex, rats were injected bilaterally with the retrograde tracer, $\mathrm{CTb}$, into the prelimbic cortex and Fos expression in CTb-labeled cells in the VTA was assessed following testing for shock-induced reinstatement or under shock-free conditions. As expected, footshock reinstated extinguished cocaine seeking (Fig. 2A). An unpaired $t$ test showed that cocaine seeking (two-tailed $t_{(11)}=4.80$; $p<0.001$ ), but not responding on a previously inactive lever (two-tailed $t_{(11)}=1.51 ; p>0.05$ ), was significantly increased following footshock relative to non-shocked controls.

Fos data are reported as the number of Fos-positive cells per $\mathrm{mm}^{2}$ (Fig. $2 \mathrm{~B}$ ), the number of dual labeled Fos-positive and CTbpositive cells per $\mathrm{mm}^{2}$ (Fig. $2 \mathrm{C}$ ), and the percentage CTb-positive cells expressing Fos (Fig. 2D) in the VTA following behavioral testing under shock and shock-free conditions. The area of cell counting in the VTA is depicted in Figure 2E. CTb injection sites in the prelimbic cortex are shown in Figure $2 F$. Six rats were excluded from analyses due to misplaced CTb injections or excessive $\mathrm{CTb}$ spread into brain regions adjacent to the prelimbic cortex, leaving final sample sizes of $n=5$ for the no shock group and $n=6$ for the shock group. Figure 2, $G$ (No Shock) and $H$ (Shock), are representative images showing immunolabeling for Fos and CTb in the VTA from each group. Shock-induced reinstatement was associated with an increase in the total number of Fos-positive cells per $\mathrm{mm}^{2}$ in the VTA (two-tailed $t_{(9)}=4.33 ; p=$ 0.002; Fig. 2B). Moreover, both the total number (Fig. $2 C$; twotailed $t_{(9)}=5.71 ; p=0.042$ ) and percentage (Fig. 2D; two-tailed $t_{(9)}=2.26$; $p<0.001$; Fig. $2 D$ ) of CTb-positive neurons in the VTA that were colabeled for Fos (per $\mathrm{mm}^{2}$ ) were significantly increased in rats tested for shock-induced reinstatement com- 

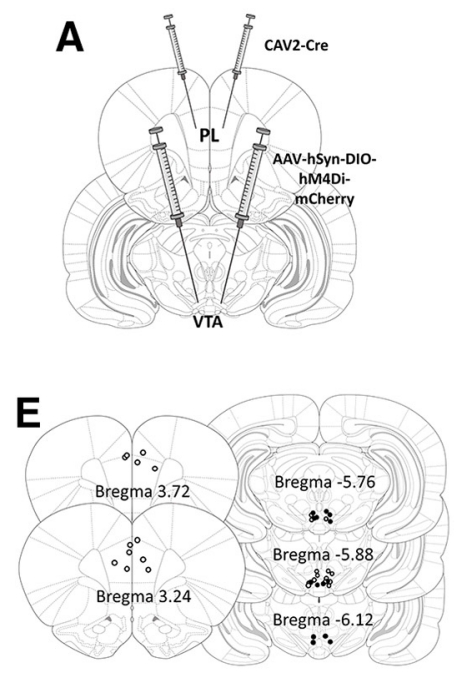
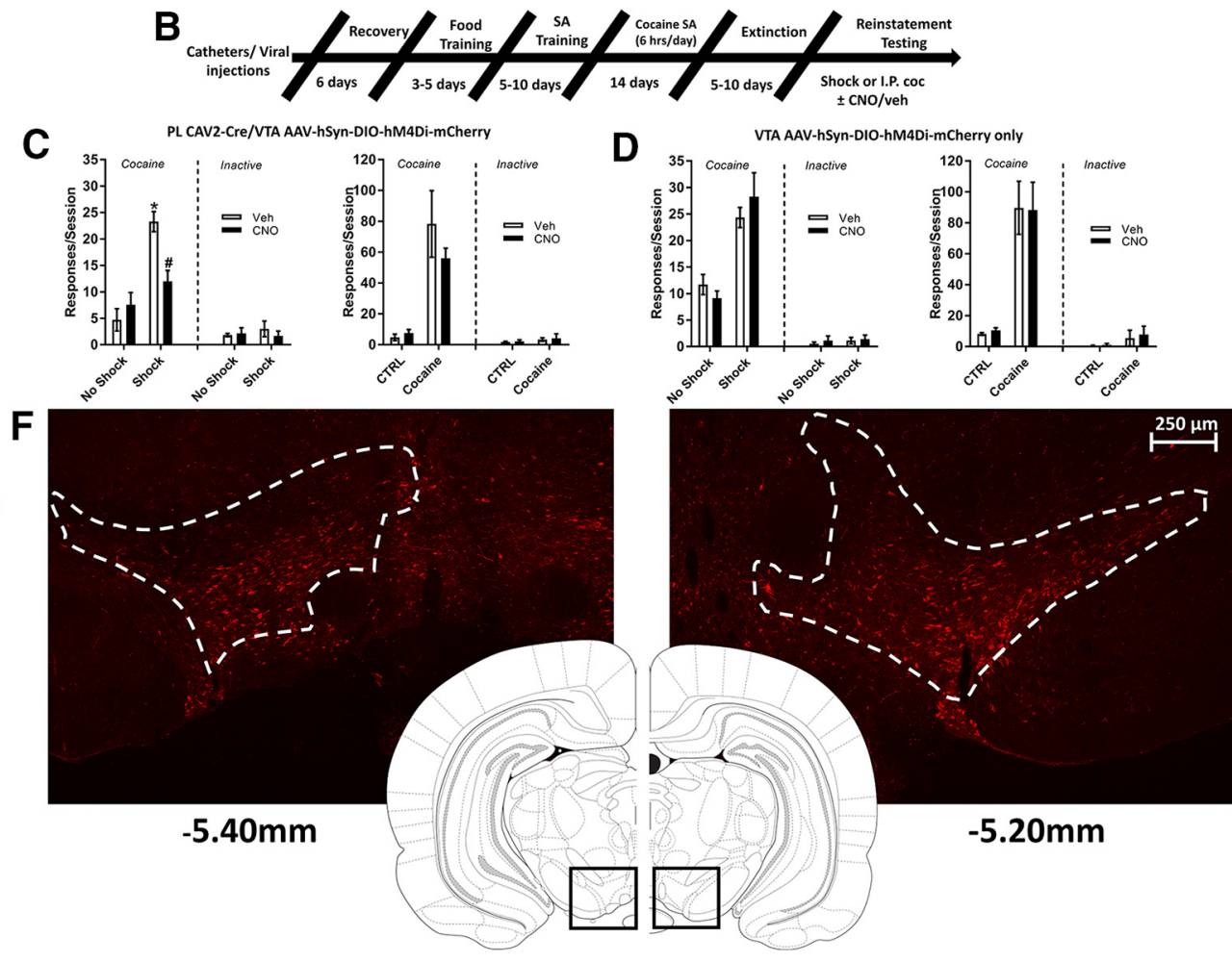

Figure 3. Stressor-induced cocaine seeking is attenuated by chemogenetic inhibition of neurons that project from the VTA to the prelimbic cortex (PL). An intersectional chemogenetic approach involving CAV2-Cre delivery into the PL and AAV delivery of a double-floxed inverted orientation (DIO) inhibitory designer receptor exclusively activated by designer drug (DREADD) vector (hSyn-DI0-hM4Di-mCherry) into the VTA was used to determine the effects of inhibition of PL-projecting VTA neurons on cocaine seeking $(\boldsymbol{A}, \boldsymbol{B})$. Administration of the DREADD agonist, CNO (1 $\mathrm{mg} / \mathrm{kg}$, i.p.) prevented shock-induced cocaine seeking in DREADD-expressing rats but not control rates that received the VTA AAV-hSyn-DI0-hM4Di-mCherry injection without PL-CAV2-Cre delivery (C). Shock increased cocaine seeking (but not inactive lever pressing) compared with non-shocked controls in vehicle- but not CNO-pretreated DREADD-expressing rats $\left({ }^{*} p=0.002\right)$ and shock-induced cocaine seeking was lower in rats pretreated with CNO relative to vehicle ( $\left.{ }^{\sharp} p=0.007\right)$. By contrast, neither cocaine seeking nor inactive lever pressing following a $10 \mathrm{mg} / \mathrm{kg}$ (i.p.) cocaine-priming injection was altered by CNO in DREADD-expressing or control rats (D). Corresponding extinction and self-administration data are depicted in Figure 3-1, available at https://doi.org/ 10.1523/JNEUROSCI.2080-18.2018.f3-1. PL and/or VTA injection sites in dual virus (open circles) and control rats (closed circles) are depicted in $\boldsymbol{E}$. $\boldsymbol{F}$, Representative image showing mCherry expression in the VTA from a rat that received injections of both VTA AAV-hSyn-DI0-hM4Di-mCherry and PL-CAV2-Cre. A representative image showing expression in TH-positive VTA neurons is included in Figure 3-2, available at https://doi.org/10.1523/JNEUROSCI.2080-18.2018.f3-2. The effects of a higher (i.e., $3 \mathrm{mg} / \mathrm{kg}$, i.p.) CN0 dose on shock-induced cocaine seeking are depicted in Figure 3-3, available at https://doi.org/10.1523/JNEUROSCI.2080-18.2018.f3-3. All data represent mean \pm SE.

pared with rats tested in the absence of shock, suggesting that shock-induced cocaine seeking is associated with activation of VTA neurons that project to the prelimbic cortex. When interpreting these data, it is important to recognize that, in addition to being taken up by nerve terminals and being transported retrogradely, CTb can be taken up by fibers of passage and transported retrogradely or anterogradely to distal sites (Chen and AstonJones, 1995). Thus, it is possible that some VTA fibers projecting to more dorsal and rostral aspects of the prefrontal cortex may have contributed to CTb labeling in the VTA.

\section{Experiment 3: effects of chemogenetic inhibition of VTA neurons that project to the prelimbic cortex on shock- induced cocaine seeking}

Chemogenetic inhibition of VTA neurons projecting to the prelimbic cortex prevented shock-induced but not cocaine-primed reinstatement of drug seeking. Nine rats received bilateral injections of CAV2-Cre into the prelimbic cortex and AAVhSyn-DIO-hM4Di-mCherry into the VTA before cocaine selfadministration, extinction and reinstatement testing (Fig. $3 A, B)$. One rat was excluded from analysis due to an inaccurate viral injection, reflected also by a lack of mCherry expression in the VTA and another died before reinstatement testing. Histologically confirmed injection sites for the remaining rats are shown in Figure 3E. Each of these rats expressed mCherry in the VTA
(Fig. 3F). Overall, $67.5 \%$ of mCherry expression was within the confines of the VTA (average of 267 cells per hemisphere), the most robust expression between -5.2 and $-5.6 \mathrm{~mm}$ relative to bregma. The remaining expression was largely in regions adjacent to the VTA known to project to the prelimbic cortex, most notably the medial substantia nigra and the midline nuclei (rostral linear nucleus and the interfascicular nucleus; Swanson, 1982; Loughlin and Fallon, 1984). Additionally, some expression was observed adjacent to the dorsomedial aspect of the VTA (medial and ventral to the red nucleus), an area not defined by Paxinos and Watson (2013). Colabeling with TH in the VTA in a subset of five rats revealed that $72.5 \%$ of mCherry-expressing neurons were TH-positive (Fig. 3-2, available at https://doi.org/10.1523/ JNEUROSCI.2080-18.2018.f3-2). Rats were tested for the effects of both 1 and $2 \mathrm{mg} / \mathrm{kg} \mathrm{CNO}$ and vehicle on baseline lever pressing and shock-induced and cocaine-primed cocaine seeking. The effects of $1 \mathrm{mg} / \mathrm{kg} \mathrm{CNO}$ on cocaine seeking in CAV2-Cre/AAVhSyn-DIO-hM4Di-mCherry infected rats are shown in Figure $3 C$. $\mathrm{CNO}(1 \mathrm{mg} / \mathrm{kg})$ prevented shock-induced cocaine seeking in these rats. A two-way repeated measures $\mathrm{CNO} \times$ shock ANOVA revealed significant shock $\times \mathrm{CNO}$ interaction $\left(F_{(1,6)}=5.69 ; p=\right.$ $0.05)$. Post hoc testing revealed that, relative to no-shock conditions, shock significantly increased cocaine seeking in vehicle $(p=0.002)$ but not CNO pretreated rats $(p>0.05)$. Moreover, shock-induced cocaine seeking was lower in CNO-pretreated 
compared with vehicle-pretreated animals $(p=0.007)$. Inactive lever responding was not significantly affected by shock or $\mathrm{CNO}$ (two-way shock $\times$ CNO ANOVA; no main effect of shock: $F_{(1,6)}=0.74$, or CNO: $F_{(1,6)}=3.11$, and no interaction: $F_{(1,6)}=$ $1.70 ; p>0.05)$. By contrast this dose of $\mathrm{CNO}$ failed to significantly reduce cocaine-primed reinstatement (Fig. $3 C$; significant main overall effect of cocaine: $\left.F_{(1,5)}=35.64 ; p=0.002\right)$ but no effect of CNO $\left(F_{(1,5)}=0.94 ; p>0.05\right)$ or cocaine $\times$ CNO interaction $\left(F_{(1,5)}=0.73 ; p>0.05\right)$. Inactive lever responding was not significantly affected by shock, cocaine, or CNO (two-way cocaine $\times$ CNO ANOVA; no main effect of cocaine: $F_{(1,5)}=1.88$, or CNO: $F_{(1,5)}=0.19$, and no interaction: $\left.F_{(1,5)}=0.19 ; p>0.05\right)$.

A second group of control rats $(n=6)$ received bilateral injections of AAV-hSyn-DIO-hM4Di-mCherry into the VTA but no prelimbic CAV2-Cre injections (for injections sites, see Fig. $3 E)$. CNO (1 mg/kg) failed to alter either shock-induced or cocaine-primed drug seeking in these rats (Fig. 3D). Two-way repeated-measures ANOVAs showed significant main overall effects of shock $\left(F_{(1,5)}=30.97 ; p=0.003\right)$ and cocaine $\left(F_{(1,5)}=\right.$ 90.61; $p<0.001)$ but no effects of $\mathrm{CNO}\left(F_{(1,5)}=0.52, p>0.05\right.$ for the shock analysis; $F_{(1,5)}=0.001, p>0.05$ for the cocaine analysis) or interactions between $\mathrm{CNO}$ and shock or cocaine $\left(F_{(1,5)}=6.17, p>0.05\right.$ for the shock analysis; $F_{(1,5)}=0.014, p>$ 0.05 for the cocaine analysis). Inactive lever responding was not significantly affected in rats tested for either shock (two-way shock $\times$ CNO ANOVA; no main effect of shock: $F_{(1,5)}=1.62$, or CNO: $F_{(1,5)}=1.00$, and no interaction: $\left.F_{(1,5)}=0.17 ; p>0.05\right)$ or cocaine-primed (two-way cocaine $X$ CNO ANOVA; no main effect of cocaine: $F_{(1,5)}=0.14$, or CNO: $F_{(1,5)}=2.43$, and no interaction: $\left.F_{(1,5)}=0.12 ; p>0.05\right)$ reinstatement.

Rats were also tested for the effects of $2 \mathrm{mg} / \mathrm{kg}$ CNO on shockinduce cocaine seeking. Surprisingly, this dose of CNO increased cocaine seeking on its own in CAV2-Cre/AAV-hSyn-DIOhM4Di-mCherry infected rats and appeared to be behaviorally active in controls rats (Fig. 3-3, available at https://doi.org/ 10.1523/JNEUROSCI.2080-18.2018.f3-3). In rats that received bilateral injections of CAV2-Cre into the prelimbic cortex and AAV-hSyn-DIO-hM4Di-mCherry into the VTA, a two-way repeated-measures ANOVA revealed a significant interaction between $\mathrm{CNO}$ and shock $\left(F_{(1,6)}=14.80 ; p=0.008\right.$; Fig. 3-3A, available at https://doi.org/10.1523/JNEUROSCI.2080-18.2018. f3-3). Shock reinstated cocaine seeking in vehicle-pretreated $\left.{ }^{*} p=0.005\right)$ but not CNO-pretreated $(p>0.05)$ rats. However, CNO by itself increased cocaine seeking in these rats $(p=0.01)$. In control rats that received AAV-hSyn-DIO-hM4Di-mCherry injections into the VTA but no CAV2-Cre injections, there was an overall effect of shock $\left(F_{(1,5)}=12.57 ;{ }^{\star} p=0.016\right.$; Fig. $3-3 B$, available at https://doi.org/10.1523/JNEUROSCI.2080-18.2018. f3-3) but no significant effect of $\mathrm{CNO}\left(F_{(1,5)}=0.36 ; p>0.05\right)$ or $\mathrm{CNO} \times$ shock interaction $\left(F_{(1,5)}=0.90 ; p>0.05\right)$. However, 2 $\mathrm{mg} / \mathrm{kg} \mathrm{CNO}$ also tended to increase drug seeking on its own in these rats.

Experiment 4: role of VTA CRFR1 receptors in shock-induced cocaine seeking and cortical subregion activation

Bilateral intra-VTA injections of the CRFR1 antagonist, antalarmin (500 ng/side), prevented shock-induced cocaine seeking in rats following $\operatorname{LgA}$ cocaine self-administration and extinction and eliminated the corresponding increase in the number of Fosimmunoreactive neurons in the prelimbic cortex. Antalarmin/ vehicle injection sites in the VTA are shown in Figure $4 A$. Figure $4 B$ shows the effects of intra-VTA antalarmin on shock-induced cocaine seeking. A two-way shock condition (shock vs no shock) $\times$ antalarmin pretreatment (VTA antalarmin vs vehicle) ANOVA showed a significant shock $X$ antalarmin interaction $\left(F_{(1,13)}=20.56 ; p=0.017\right)$. Post hoc testing revealed that shockinduced cocaine seeking was observed following intra-VTA vehicle injections ( $p=0.011$ vs shock-free controls) but not after intra-VTA antalarmin delivery $(p>0.05)$. Moreover, cocaine seeking in rats that received intra-VTA antalarmin injections before shock delivery was significantly lower than in intra-VTA vehicle controls $(p<0.001)$.

Figure $4 C$ shows the effects of intra-VTA antalarmin on the Fos response (Fos-positive cells per $\mathrm{mm}^{2}$ ) to shock in the prelimbic cortex. A two-way antalarmin $\times$ shock-induced reinstatement ANOVA showed a significant interaction between shock and antalarmin pretreatment $\left(F_{(1,13)}=77.86 ; p<0.001\right)$. Shock increased the number of Fos-immunoreactive cells per $\mathrm{mm}^{2}$ in the prelimbic cortex in vehicle-pretreated $(p<0.001)$ but not antalarmin-pretreated rats $(p>0.05)$ relative to non-shocked controls, and the number of Fos-immunoreactive cells in the prelimbic cortex following shock was reduced in antalarminpretreated rats relative to vehicle controls $(p<0.001)$. In the infralimbic cortex, neither intra-VTA antalarmin nor shock produced overall increases in the number of Fos-positive cells, but a significant shock $\times$ antalarmin interaction was observed $\left(F_{(1,13)}=\right.$ $6.33 ; p=0.026$; Fig. $4 D$ ). Shock increased infralimbic Fos immunoreactivity in intra-VTA vehicle $(p=0.039)$, but not antalarmin $(p>0.05)$, pretreated rats. Immunolabeled sections including the prelimbic cortex from representative rats that received VTA vehicle or antalarmin are shown in Figure $4 E$ and $F$.

\section{Experiment 5: effect of pharmacological disconnection of the CRF-regulated dopaminergic pathway from the VTA to the prelimbic cortex on shock-induced cocaine seeking}

To determine the role of a CRFR1 regulated pathway originating in the VTA that releases dopamine into the prelimbic cortex in stress-induced cocaine seeking, we used a disconnection approach in which we delivered antalarmin (500 ng) into the VTA of one hemisphere and the dopamine D1 receptor antagonist, SCH 23390 (200 ng) into the contralateral prelimbic cortex (Fig. $5 A$; final $n=7$ after 3 rats were excluded because of cannula misplacement). A two-way repeated-measures shock condition ( shock vs no shock) $\times$ disconnection (antalarmin/SCH 23390 vs veh/veh) ANOVA revealed a significant shock $\times$ disconnection interaction $\left(F_{(1,6)}=10.38 ; p=0.018\right)$. Post hoc testing showed that shock increased cocaine seeking relative to shock-free controls in rats that received contralateral VTA/prelimbic vehicle injections $(p=0.007)$ but not in rats that underwent pharmacological disconnection $(p>0.05)$. Moreover, cocaine seeking following shock was significantly lower in rats that received contralateral VTA antalarmin/prelimbic SCH 23390 relative to vehicle/vehicle controls ( $p=0.017)$. Unexpectedly, in contrast to the other experiments assessing shock-induced cocaine seeking, a significant (albeit small) overall effect of shock on inactive lever pressing was observed $\left(F_{(1,6)}=9.39 ; p=0.022\right)$. However, no overall effect of disconnection $\left(F_{(1,6)}=0.48 ; p>0.05\right)$ or shock $\times$ disconnection interaction $\left(F_{(1,6)}=0.30\right)$ was observed.

To confirm that the effects of contralateral drug delivery on cocaine seeking were attributable to pathway disconnection, a second group of rats (Fig. $5 B ; n=7$ after exclusion of one rat because of cannula misplacement) received antalarmin into the VTA of one hemisphere and SCH 23390 into the ipsilateral prelimbic cortex. In contrast to rats that received antagonists into the contralateral regions, administration of antalarmin and SCH23390 to the VTA/prelimbic cortex within the ipsilateral 

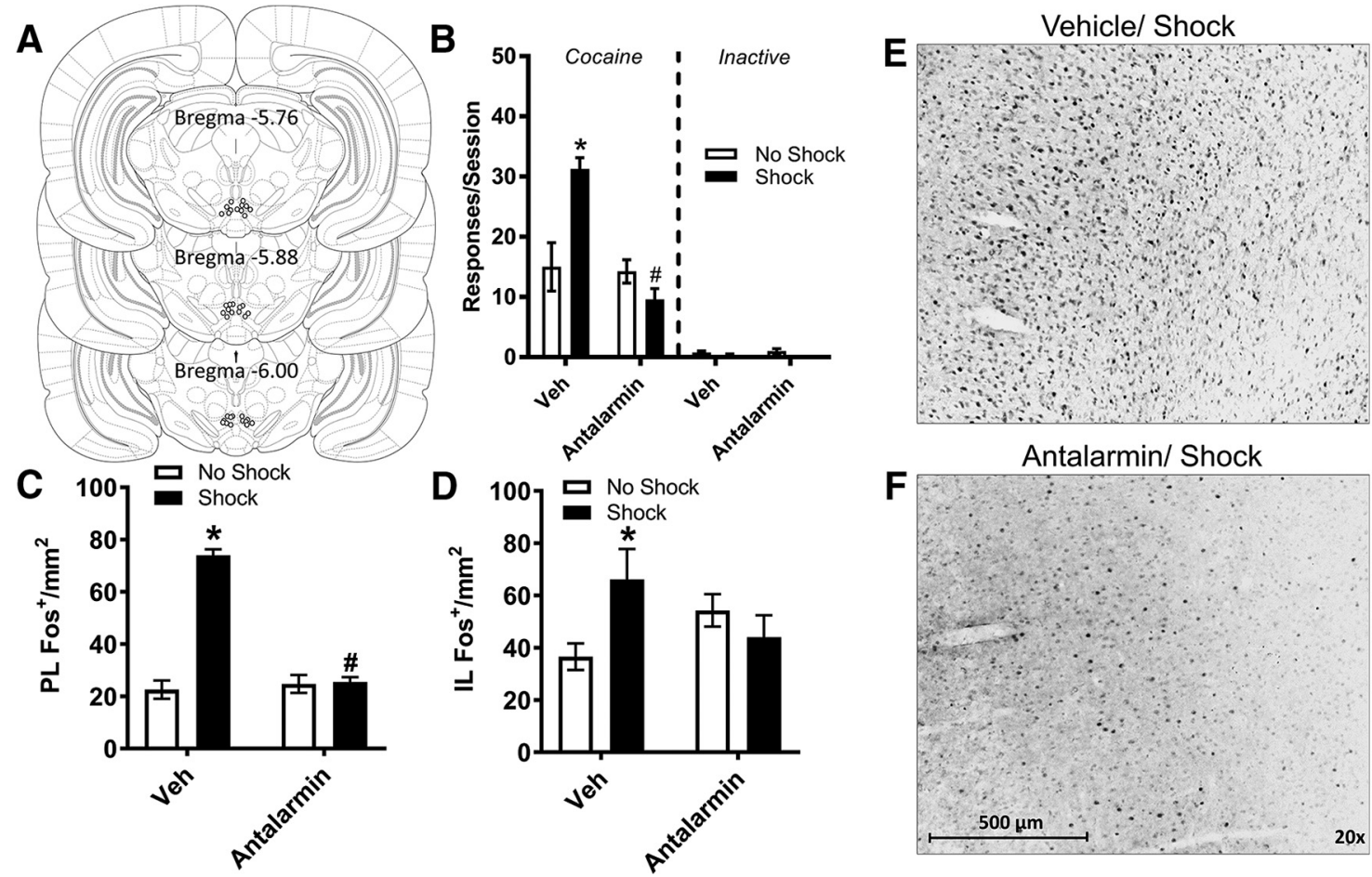

Figure 4. CRFR1 antagonism in the VTA prevents shock-induced cocaine seeking and the corresponding Fos response in the prelimbic cortex. Bilateral intra-VTA injection sites for the CRFR1 antagonist, antalarmin ( $500 \mathrm{ng} /$ side) or vehicle, are shown in $\boldsymbol{A}$. Shock reinstated cocaine seeking in vehicle control rats ( ${ }^{*} p=0.011 \mathrm{vs} \mathrm{No} \mathrm{Shock} \mathrm{controls),} \mathrm{and} \mathrm{intra-VTA} \mathrm{antalarmin} \mathrm{prevented}$ shock-induced cocaine seeking ( $\boldsymbol{B} ;{ }^{\#} p<0.001$ vs intra-VTA Veh controls). Neither shock nor antalarmin effects on inactive lever responding were observed. Intra-VTA antalarmin also prevented the corresponding increases in the numbers of Fos-positive cells $\left(\right.$ per mm $\left.{ }^{2}\right)$ in the prelimbic cortex $\left(C_{;}^{*} p<0.001\right.$, increase vs No Shock controls in Veh but not Antalarmin rats; ${ }^{*} p<0.001$, Fos reduction intra-VTA antalarmin vs veh pretreatment) and infralimbic cortex ( $\boldsymbol{D} ;{ }^{*} p=0.039$, increase vs No Shock controls in Veh but not Antalarmin rats). Representative images showing the Fos responses in the prelimbic cortex following intra-VTA vehicle or antalarmin injections are shown in $\boldsymbol{E}$ and $\boldsymbol{F}$. Corresponding extinction and self-administration data are depicted in Figure 4-1, available at https://doi.org/10.1523/JNEUROSCI.2080-18.2018.f4-1. All data represent mean \pm SE.

hemisphere did not prevent shock-induced cocaine seeking. A two-way shock condition (shock vs no shock) $\times$ ipsilateral drug treatment (antalarmin/SCH $23390 \mathrm{vs}$ veh/veh) repeated-measures ANOVA revealed a significant main effect of shock $\left(F_{(1,6)}=\right.$ 13.83; $p=0.010)$. However, in contrast to contralateral drug administration no main effect of $\left(F_{(1,6)}=0.19 ; p>0.05\right)$ or interactions $\left(F_{(1,6)}=4.80 ; p>0.05\right)$ involving antagonist administration were observed. No effects on inactive lever responding were observed (two-way shock $\times$ disconnection ANOVA; no main effect of shock: $F_{(1,6)}=1.79$, or disconnection: $F_{(1,6)}=0.05$, and no interaction: $\left.F_{(1,6)}=0.45 ; p>0.05\right)$.

In contrast to the prelimbic cortex, disconnection of the pathway from the VTA to the infralimbic cortex through antalarmin delivery into the VTA in one hemisphere and SCH 23390 delivery into the infralimbic cortex of the other hemisphere failed to alter shock-induced cocaine seeking (Fig. $5 C ; n=5$ after exclusion of two rats due to cannula misplacements). A two-way repeatedmeasures condition (shock vs no shock) $\times$ disconnection (antalarmin/SCH 23390 vs veh/veh) ANOVA revealed a significant overall effect of shock $\left(F_{(1,4)}=33.39 ; p=0.015\right)$ but no main effect of disconnection $\left(F_{(1,4)}=2.19 ; p>0.05\right)$ or shock $\times$ disconnection interaction $\left(F_{(1,4)}=4.92 ; p>0.05\right)$, indicating shock-induced reinstatement of cocaine seeking relative to nonshock controls, regardless of drug pretreatment. Effects on inactive lever responding were not observed (two-way shock $\times$ disconnection ANOVA; no main effect of shock: $F_{(1,4)}=2.20$, or disconnection: $F_{(1,4)}=0.56$, and no interaction: $F_{(1,4)}=0.93 ; p>$ $0.05)$. VTA antalarmin/veh and cortical SCH 23390/veh injection sites are shown in Figure 5D.
Experiment 6: effects of cocaine self-administration under conditions that promote shock-induced cocaine seeking on CRFR1 mRNA in the VTA

To determine whether the recruitment of the CRF-regulated pathway from the VTA to the prelimbic cortex was associated with an increase in CRFR1 expression, in situ hybridization was used to quantify VTA CRFR1 mRNA levels following selfadministration and extinction in rats provided access to cocaine under ShA and LgA conditions and saline controls (for representative VTA area of quantitation, see Fig. $6 A$; A/P zone of measurement extended from -5.2 to $-6.0 \mathrm{~mm}$ referenced to bregma). Mean integrated IODs are shown in Figure 6B. One-way ANOVA was used to compare VTA CRFR1 mRNA levels across selfadministration conditions. A significant overall effect of access condition was found $\left(F_{(2,23)}=6.95 ; p=0.005\right)$. Post hoc testing showed that CRFR1 mRNA was increased relative to saline controls following LgA, but not ShA, self-administration and extinction $(p=0.004)$. Representative images of brain sections hybridized with CRFR1 riboprobe from each group are shown in Figure $6 C-E$. To determine whether the effects of cocaine selfadministration on CRFR1 mRNA were also observed in adjacent brain regions, we assessed mRNA levels in the substantia nigra reticulata $(\mathrm{SNr})$ and adjacent aspects of the red nucleus $(\mathrm{RN})$, both regions known to express CRFR1 (Van Pett et al., 2000). In each case, CRFR1 mRNA levels did not differ across selfadministration conditions (SNr: SalIOD: $13.58 \pm 1.57$; ShA IOD: $24.48 \pm 9.85$; LgA IOD: $25.12 \pm 47.51$; one-way ANOVA, $F_{(2,18)}=0.71 ; p>0.05$; RN: SalIOD: $10.65 \pm 2.99$; ShA IOD: 
A Contralateral VTA/PL Cortex

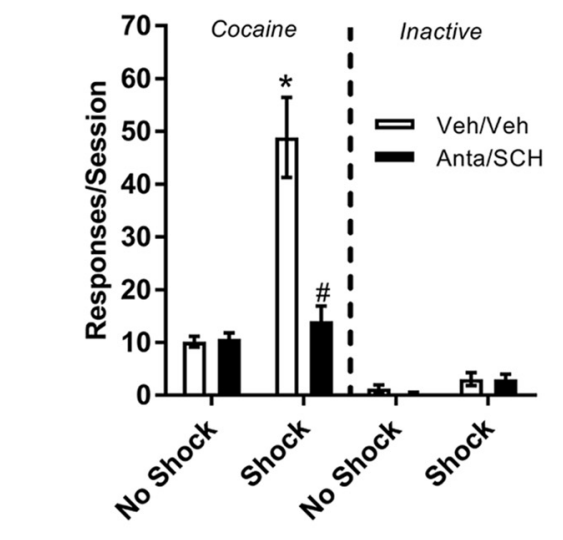

C

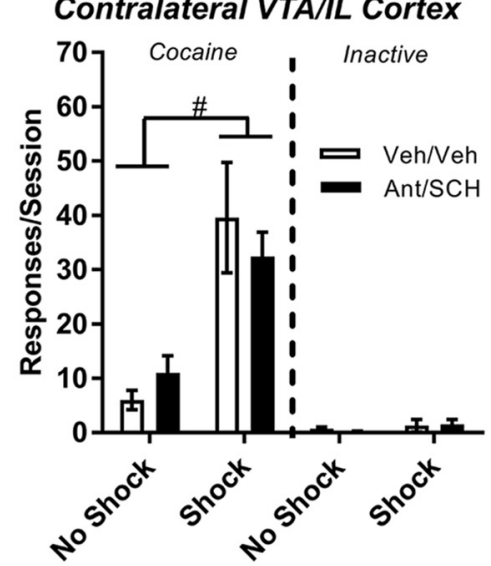

B
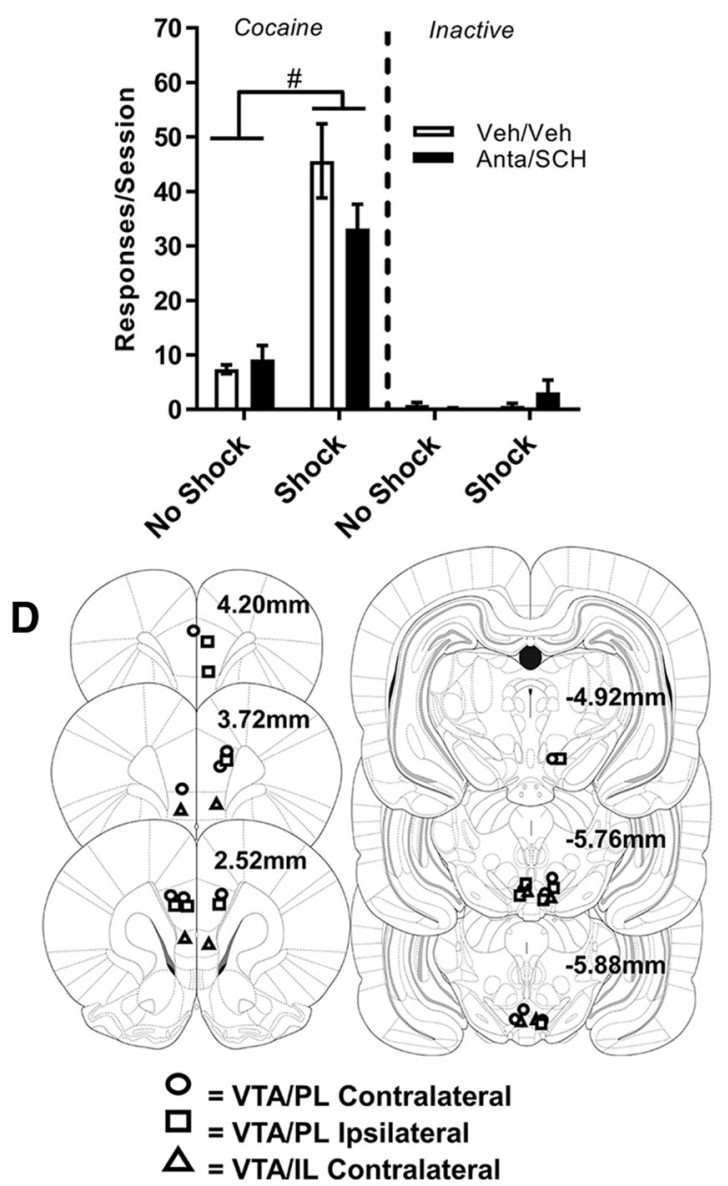

Figure 5. A CRFR1-regulated dopaminergic projection to the prelimbic cortex is required for stress-induced cocaine seeking. To determine the role of a CRFR1-regulated dopaminergic projection from the VTA to the prelimbic cortex in stress-induced cocaine seeking, we used a disconnection approach in which we delivered antalarmin (500 ng) into the VTA of one hemisphere and SCH23390 $(200 \mathrm{ng})$ into the contralateral prelimbic cortex $(n=7)$ and tested for shock-induced cocaine seeking. To confirm that any effect on reinstatement was attributable to pathway disconnection, a second group of rats $(n=7)$ received an antalarmin injection into the VTA of one hemisphere and a SCH23390 injection into the ipsilateral prelimbic cortex. Significant shock-induced reinstatement was observed following contralateral VTA/prelimbic cortex vehicle injections (Veh/Veh, $\left.{ }^{*} p=0.007\right)$ but not following contralateral antagonist delivery (Ant/SCH, $\left.p>0.05 ; \boldsymbol{A}\right)$. Moreover, shock-induced reinstatement was significantly reduced following contralateral VTA/prelimbic cortex antagonist injections relative to vehicle/vehicle injections ( ${ }^{*} p=0.017$ ). By contrast, neither ipsilateral antagonist delivery $(\boldsymbol{B})$ nor disconnection of the VTA pathway to the infralimbic cortex $(\boldsymbol{C} ; n=5)$ significantly altered shock-induced cocaine seeking. In both cases significant main effects of shock ( ${ }^{*} p=0.010$ for ipsilateral prelimbic rats; ${ }^{*} p=0.015$ for contralateral infralimbic rats) but no effects of or interactions with antagonist delivery were observed. Intra-VTA and cortical injection sites for rats used for analysis are shown in $\boldsymbol{D}$ (circles, contralateral prelimbic/VTA; squares, ipsilateral prelimbic/VTA; triangles, contralateral infralimbic/VTA). Corresponding extinction and self-administration data are depicted in Figure 5-1, available at https://doi.org/10.1523/JNEUROSCI.2080-18.2018.f5-1. All data represent mean \pm SE.

$15.35 \pm 5.85$; LgA IOD: $10.56 \pm 4.35$; one-way ANOVA, $F_{(2,18)}=$ $0.35 ; p>0.05)$.

\section{Discussion}

Stress-induced cocaine seeking is determined by the amount/pattern of prior self-administration

Although stress has been identified as a contributor to relapse, its relationship with drug seeking is complex. The onset of stress does not always serve as a reliable trigger for cocaine use (Preston and Epstein, 2011; Furnari et al., 2015). A key determinant of stress-induced cocaine seeking is the extent/pattern of prior use. High-frequency cocaine abusers display increased drug craving, anxiety and associated physiological responses upon exposure to stress imagery compared with lower-frequency abusers (Fox et al., 2005). Consistent with this observation, we find that reliable stress-induced cocaine seeking is observed in rats with a history of cocaine self-administration under long- but not short-access conditions (Mantsch et al., 2008).
Intake-dependent increase in activation of the prelimbic cortex during stress-induced cocaine seeking

A glutamatergic projection from the prelimbic cortex to nucleus accumbens core appears to be critical for cocaine seeking (Stefanik et al., 2013, 2016). Inhibition of this pathway using baclofen/muscimol (McFarland et al., 2004) or tetrodotoxin (Capriles et al., 2003) delivery into the prelimbic cortex prevents stress-induced cocaine seeking and the corresponding increase in nucleus accumbens core glutamatergic neurotransmission (McFarland et al., 2004). Here we demonstrate that stress-induced reinstatement is associated with a heightened prelimbic cortical Fos response, consistent with activation of this cortico-accumbens pathway.

Role for a CRFR1-regulated mesocortical dopaminergic pathway in stress-induced cocaine seeking Although the prelimbic cortex receives afferents from many stressor-responsive structures, inputs from the VTA, which has 

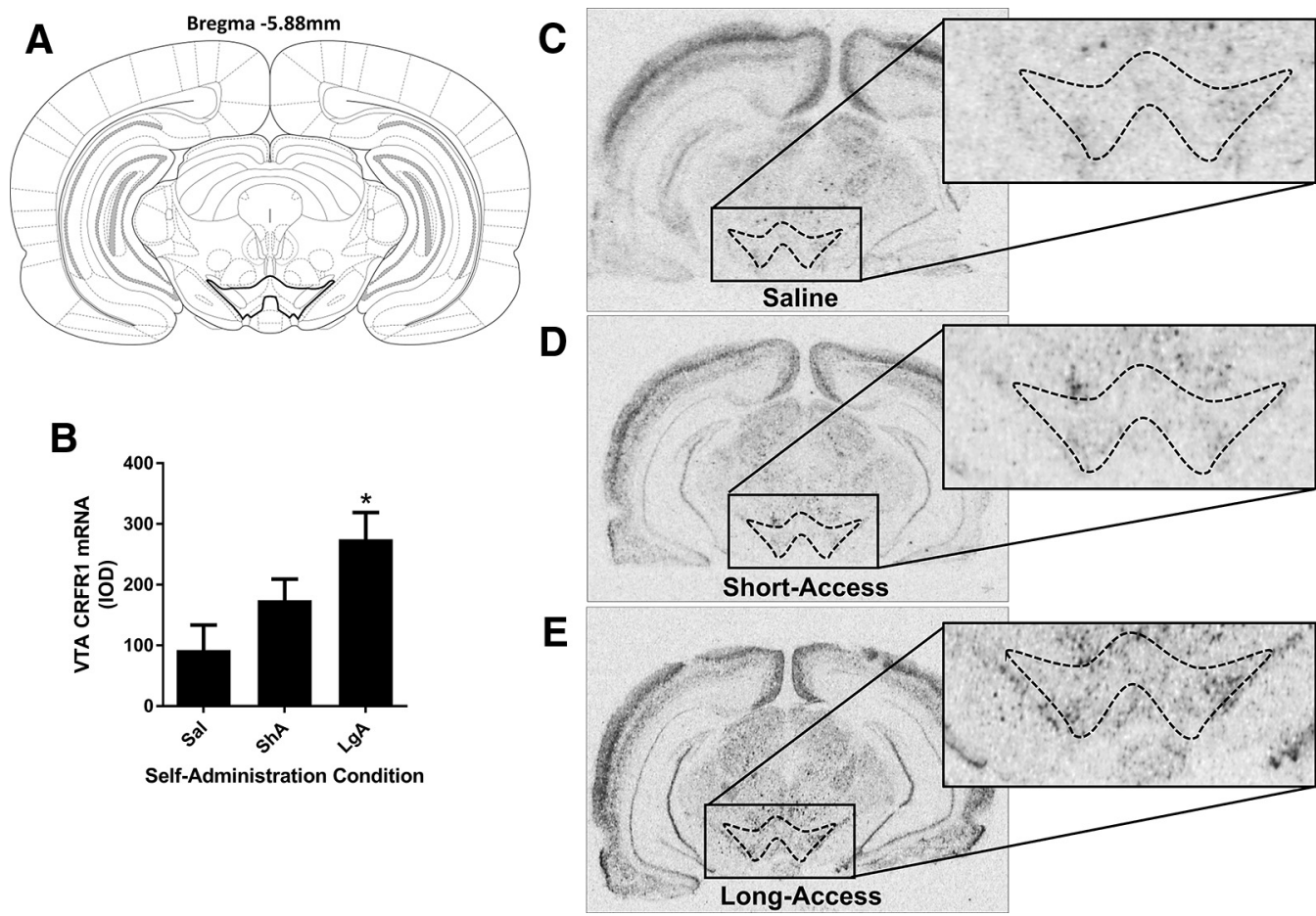

Figure 6. Cocaine self-administration under conditions that establish CRF-dependent shock-induced cocaine seeking and corresponding activation of the prelimbic cortex increases CRFR1 mRNA in the VTA. CRFR1 receptor mRNA levels in the VTA were quantified by in situ hybridization using a ${ }^{35}$ S-labeled CRFR1 riboprobe. The field of quantitation is depicted in $A$. Mean IODs reflecting CRFR1 $m R N A$ levels in the VTA ( -5.2 to $-6.0 \mathrm{~mm}$ relative to bregma) are shown in $B$. CRFR1 mRNA levels were significantly increased in the VTA following LgA self-administration, but not ShA cocaine self-administration relative to saline controls ( ${ }^{*} p=0.004 ; n=8 /$ group). Representative images of film exposed to hybridized sections containing VTA from rats following self-administration under ShA, LgA, or saline control conditions are shown in C-E. Corresponding extinction and self-administration data are depicted in Figure 6-1, available at https://doi.org/10.1523/JNEUROSCI.208018.2018.f6-1. All data represent mean \pm SE.

been implicated in stress-induced cocaine seeking (Capriles et al., 2003; McFarland et al., 2004) are likely important for the shockinduced Fos response and corresponding cocaine seeking. Accordingly, we observed Fos immunoreactivity in VTA neurons projecting to the prelimbic cortex during shock-induced cocaine seeking and found that chemogenetic inhibition of these neurons prevents shock-induced reinstatement. These findings are consistent with a report by Deutch et al. (1991) demonstrating a similar stress-induced response in cocaine-naive rats. In that study, restraint activated VTA neurons that project to prefrontal cortex without affecting those projecting to nucleus accumbens, consistent with reports that the mesocortical dopamine pathway is selectively activated by aversive stimuli (Lammel et al., 2012). Although it is possible that this mesocortical pathway selectively mediates stress-induced drug seeking, we did not assess Fos responses in other subpopulations of VTA neurons or their contributions to drug seeking.

Inhibiting VTA neurons that project to the prelimbic cortex did not affect reinstatement induced by a cocaine priming injection. This was unexpected, considering previous work implicating the prefrontal cortex in cocaine-primed reinstatement (McFarland and Kalivas, 2001; Capriles et al., 2003; McFarland et al., 2003). However, others have reported that prelimbic cortical dopamine receptor antagonism does not affect cocaine-primed drug seeking (Capriles et al., 2003; but see McFarland et al., 2004), suggesting that the contribution of the structure may be independent of the mesocortical pathway. To the extent that dopamine is involved, cocaine could produce effects (e.g., reduced dopamine clearance) that promote receptor activation in the absence of increased mesocortical neuronal firing. The lack of effect of pathway inhibition on cocaine-primed reinstatement and the failure of $1 \mathrm{mg} / \mathrm{kg} \mathrm{CNO}$ to alter drug seeking in rats that do not express hM4Di argue against a contribution of nonspecific behavior suppression to reduced shock-induced cocaine seeking.

Converging evidence suggests that shock triggers cocaine seeking via CRFR1-dependent activation of mesocortical neurons and cortical D1 receptors. First, $72.5 \%$ of hM4Di-expressing VTA neurons were TH-positive (Fig. 3-2, available at https:// doi.org/10.1523/JNEUROSCI.2080-18.2018.f3-2). Second, intraVTA injections of the CRFR1 antagonist, antalarmin, prevent shock-induced cocaine seeking and corresponding increases in prelimbic Fos expression. Third, shock-induced reinstatement is prevented using an asymmetric pharmacological disconnection approach wherein antalarmin is injected into the VTA of one hemisphere and the $\mathrm{D} 1$ receptor antagonist, $\mathrm{SCH} 23390$, into the contralateral prelimbic cortex. Based on past results, we hypothesize that, during stress, CRF released into the VTA, likely from neurons originating in the BNST (Rodaros et al., 2007; Silberman et al., 2013; Vranjkovic et al., 2014), activates CRFR1, possibly on mesocortical neurons, thereby promoting prelimbic dopamine release and D1 receptor activation to induce drug seeking.

\section{Contribution of prelimbic cortical D1 receptors and VTA CRFR1 to stress-induced cocaine seeking}

Our findings are consistent with reports that injections of the D1 receptor antagonist SCH23390 (Capriles et al., 2003) or the nonselective antagonist fluphenazine (McFarland et al., 2004) but not selective D2-like receptor antagonists (Capriles et al., 2003) into the prelimbic cortex prevent stress-induced cocaine seeking. Prelimbic cortical D1 receptor activation likely induces cocaine seeking via activation of a pathway to the nucleus accumbens core. Accordingly, D1 receptors in the prelimbic cortex are expressed 
in pyramidal neuron subpopulations where they promote excitability (Lewis and O'Donnell, 2000; Seamans et al., 2001; Tseng and O'Donnell, 2004).

Our findings are also consistent with the established role for VTA CRF (via CRFR1 actions) as a key regulator of the mesocortical dopamine pathway and stress-induced drug seeking. Shockinduced reinstatement is associated with increased VTA CRF levels (Wang et al., 2005) and intra-VTA CRF (Wang et al., 2005) or selective CRF-R1 agonist (Blacktop et al., 2011) injections are sufficient to reinstate. Moreover, pharmacological antagonism (Blacktop et al., 2011; Vranjkovic et al., 2014) or shRNAmediated knockdown (Chen et al., 2014) of VTA CRFR1 prevents stress-induced cocaine seeking. Although studies examining the regulation of mesocortical dopamine by VTA CRF have produced mixed results (Kalivas et al., 1987), reports that intracerebroventricular CRF increases dopaminergic neurotransmission in prefrontal cortex (Dunn and Berridge, 1987; Lavicky and Dunn, 1993) and that CRF promotes excitation of VTA dopamine neurons via presynaptic and postsynaptic mechanisms (Ungless et al., 2003; Riegel and Williams, 2008; Wanat et al., 2008; Beckstead et al., 2009; Hahn et al., 2009; Williams et al., 2014) suggest that stress-induced release of CRF into the VTA may underlie increases in mesocortical dopamine release. Consistent with this possibility, Refojo et al. (2011) reported that CRFR1 deletion in VTA dopamine neurons attenuates stressinduced increases in prefrontal cortical dopamine in mice, whereas Wang et al. (2005) demonstrated that increases in VTA dopamine levels associated with shock-induced reinstatement are CRF-dependent.

\section{Establishment of stress-induced cocaine seeking through recruitment of a CRF-regulated mesocortical dopaminergic pathway}

We hypothesize that repeated cocaine self-administration results in an intake-dependent recruitment of a CRF-regulated dopaminergic pathway from the VTA to prelimbic cortex that establishes susceptibility to stress-induced drug seeking. This hypothesis is supported by our observations that (1) cocaine seeking requires VTA CRFR1-dependent activation of the mesocortical pathway and prelimbic D1 receptor activation and is observed following long-access but not short-access self-administration, (2) the Fos response to shock in the prelimbic cortex is dependent on VTA CRFR1 and augmented following long-access relative to shortaccess self-administration, and (3) shock-induced cocaine seeking following long-access self-administration corresponds with activation of VTA neurons that project to the prelimbic cortex.

However, we did not compare Fos responses in neurons projecting to the prelimbic cortex between rats with histories of longversus short-access self-administration, and therefore do not provide direct evidence that this pathway is differentially active following shock in these two populations of rats.

It has been reported that CRF actions in the VTA vary with prior cocaine history (Wang et al., 2005; Beckstead et al., 2009; Hahn et al., 2009; Williams et al., 2014). Thus, heightened sensitivity to stress-induced cocaine seeking and the corresponding enhanced regulation of the prelimbic cortex may be attributed to increased VTA CRFR1 responsiveness resulting from prior longaccess self-administration. In support, we found that VTA CRFR1 mRNA is significantly increased in long- but not shortaccess, rats compared with saline controls, consistent with our previous finding that intra-VTA CRF-induced cocaine seeking is only observed following long-access self-administration (Blacktop et al., 2011). Notably, a less-pronounced increase in VTA
CRFR1 mRNA was observed following short-access selfadministration, suggesting that cocaine-induced changes in receptor mRNA are proportional to the amount drug consumed. Unfortunately, the lack of CRFR1-selective antibodies or reliable binding-based approaches limits our ability to confirm that differences in mRNA levels relate to changes in functional protein. However, our previous observation that cocaine seeking in response to intra-VTA CRF (working via CRFR1) is also established with long-access cocaine self-administration (Blacktop et al., 2011) is highly suggestive of functional receptor changes. Moreover, it has been reported that repeated cocaine administration increases VTA CRF binding (Goeders et al., 1990) and establishes CRFR1 regulation of excitatory transmission (Hahn et al., 2009). Although we assume that alterations in CRFR1 are localized to dopaminergic neurons, confirmation requires further investigation as CRFR1 may also be expressed in nondopaminergic cell populations that are either intrinsic to and/or project from the VTA.

\section{Potential DREADD-independent effects of $2 \mathrm{mg} / \mathrm{kg}$ CNO}

Notably, while $1 \mathrm{mg} / \mathrm{kg}$ CNO selectively prevented shockinduced cocaine seeking in hM4Di-expressing rats, a higher $\mathrm{CNO}$ dose $(2 \mathrm{mg} / \mathrm{kg})$ produced an unexpected increase in cocaine seeking in these rats in the absence of shock or a cocaine priming injection. Moreover, a similar effect of $2 \mathrm{mg} / \mathrm{kg} \mathrm{CNO}$ was observed in non-hM4Di-expressing control rats, suggestive of a DREADD-independent mechanism. CNO activation of DREADDs in the brain may involve peripheral conversion to clozapine, which, at sufficient concentrations, can interact with a number of native receptors in addition to DREADDs (Gomez et al., 2017). Indeed, it has been reported that CNO can produce a clozapine-like interoceptive state in non-DREADD-expressing rats, albeit at doses higher than the $2 \mathrm{mg} / \mathrm{kg}$ CNO dose used in our study in male Sprague-Dawley rats (>3.2 mg/kg, i.p.; Manvich et al., 2018). Thus, we consider it likely that the effects on cocaine seeking observed at our higher $\mathrm{CNO}$ dose were attributable to DREADD independent actions of CNO-derived clozapine.

\section{Conclusions}

These findings demonstrate that (1) stress-induced cocaine seeking requires activation of a CRFR1-regulated dopaminergic pathway from the VTA to prelimbic cortex and (2) repeated cocaine use may establish stress-reactivity of this pathway via CRFR1 upregulation. Although the extent to which the ability of CRFR1 antagonists to reduce drug seeking in preclinical models translates to effective clinical interventions is questionable (Shaham and de Wit, 2016), further understanding the regulation of this pathway and how it is recruited with excessive cocaine use should provide important insight into the addiction process.

\section{References}

Beckstead MJ, Gantz SC, Ford CP, Stenzel-Poore MP, Phillips PE, Mark GP, Williams JT (2009) CRF enhancement of GIRK channel-mediated transmission in dopamine neurons. Neuropsychopharmacology 34:19261935. CrossRef Medline

Blacktop JM, Seubert C, Baker DA, Ferda N, Lee G, Graf EN, Mantsch JR (2011) Augmented cocaine seeking in response to stress or CRF delivered into the ventral tegmental area following long-access self-administration is mediated by CRF receptor type 1 but not CRF receptor type 2 . J Neurosci 31:11396-11403. CrossRef Medline

Capriles N, Rodaros D, Sorge RE, Stewart J (2003) A role for the prefrontal cortex in stress- and cocaine-induced reinstatement of cocaine seeking in rats. Psychopharmacology 168:66-74. CrossRef Medline

Chen NA, Jupp B, Sztainberg Y, Lebow M, Brown RM, Kim JH, Chen A, Lawrence AJ (2014) Knockdown of CRF1 receptors in the ventral teg- 
mental area attenuates cue- and acute food deprivation stress-induced cocaine seeking in mice. J Neurosci 34:11560-11570. CrossRef Medline

Chen S, Aston-Jones G (1995) Evidence that cholera toxin B subunit (CTb) can be avidly taken up and transported by fibers of passage. Brain Res 674:107-111. CrossRef Medline

Deutch AY, Tam SY, Roth RH (1985) Footshock and conditioned stress increase 3,4-dihydroxyphenylacetic acid (DOPAC) in the ventral tegmental area but not substantia nigra. Brain Res 333:143-146. CrossRef Medline

Deutch AY, Lee MC, Gillham MH, Cameron DA, Goldstein M, Iadarola MJ (1991) Stress selectively increases fos protein in dopamine neurons innervating the prefrontal cortex. Cereb Cortex 1:273-292. CrossRef Medline

Dunn AJ, Berridge CW (1987) Corticotropin-releasing factor administration elicits a stress-like activation of cerebral catecholaminergic systems. Pharmacol Biochem Behav 27:685-691. CrossRef Medline

Fox HC, Talih M, Malison R, Anderson GM, Kreek MJ, Sinha R (2005) Frequency of recent cocaine and alcohol use affects drug craving and associated responses to stress and drug-related cues. Psychoneuroendocrinology 30:880-891. CrossRef Medline

Furnari M, Epstein DH, Phillips KA, Jobes ML, Kowalczyk WJ, Vahabzadeh M, Lin JL, Preston KL (2015) Some of the people, some of the time: field evidence for associations and dissociations between stress and drug use. Psychopharmacology 232:3529-3537. CrossRef Medline

Goeders NE, Bienvenu OJ, De Souza EB (1990) Chronic cocaine administration alters corticotropin-releasing factor receptors in the rat brain. Brain Res 531:322-328. CrossRef Medline

Gold RM (1966) Aphagia and adipsia produced by unilateral hypothalamic lesions in rats. Am J Physiol 211:1274-1276. CrossRef Medline

Gomez JL, Bonaventura J, Lesniak W, Mathews WB, Sysa-Shah P, Rodriguez LA, Ellis RJ, Richie CT, Harvey BK, Dannals RF, Pomper MG, Bonci A, Michaelides M (2017) Chemogenetics revealed: DREADD occupancy and activation via converted clozapine. Science 357:503-507. CrossRef Medline

Hahn J, Hopf FW, Bonci A (2009) Chronic cocaine enhances corticotropinreleasing factor-dependent potentiation of excitatory transmission in ventral tegmental area dopamine neurons. J Neurosci 29:6535-6544. CrossRef Medline

Hoffman GE, Murphy KJ, Sita LV (2016) The importance of titrating antibodies for immunocytochemical methods. Curr Protoc Neurosci 76: 2.12.1-2.12.37. CrossRef Medline

Hosp JA, Nolan HE, Luft AR (2015) Topography and collateralization of dopaminergic projections to primary motor cortex in rats. Exp Brain Res 233:1365-1375. CrossRef Medline

Kalivas PW, Duffy P, Latimer LG (1987) Neurochemical and behavioral effects of corticotropin-releasing factor in the ventral tegmental area of the rat. J Pharmacol Exp Ther 242:757-763. Medline

Korotkova TM, Brown RE, Sergeeva OA, Ponomarenko AA, Haas HL (2006) Effects of arousal- and feeding-related neuropeptides on dopaminergic and GABAergic neurons in the ventral tegmental area of the rat. Eur J Neurosci 23:2677-2685. CrossRef Medline

Lammel S, Ion DI, Roeper J, Malenka RC (2011) Projection-specific modulation of dopamine neuron synapses by aversive and rewarding stimuli. Neuron 70:855-862. CrossRef Medline

Lammel S, Lim BK, Ran C, Huang KW, Betley MJ, Tye KM, Deisseroth K, Malenka RC (2012) Input-specific control of reward and aversion in the ventral tegmental area. Nature 491:212-217. CrossRef Medline

Lavicky J, Dunn AJ (1993) Corticotropin-releasing factor stimulates catecholamine release in hypothalamus and prefrontal cortex in freely moving rats as assessed by microdialysis. J Neurochem 60:602-612. CrossRef Medline

Lewis BL, O'Donnell P (2000) Ventral tegmental area afferents to the prefrontal cortex maintain membrane potential "up" states in pyramidal neurons via D1 dopamine receptors. Cereb Cortex 10:1168-1175. CrossRef Medline

Loughlin SE, Fallon JH (1984) Substantia nigra and ventral tegmental area projections to cortex: topography and collateralization. Neuroscience 11: 425-435. CrossRef Medline

Lowery-Gionta EG, Navarro M, Li C, Pleil KE, Rinker JA, Cox BR, Sprow GM, Kash TL, Thiele TE (2012) Corticotropin releasing factor signaling in the central amygdala is recruited during binge-like ethanol consumption in C57BL/6J mice. J Neurosci 32:3405-3413. CrossRef Medline
Mantsch JR, Baker DA, Francis DM, Katz ES, Hoks MA, Serge JP (2008) Stressor- and corticotropin releasing factor-induced reinstatement and active stress-related behavioral responses are augmented following longaccess cocaine self-administration by rats. Psychopharmacology 195:591603. CrossRef Medline

Mantsch JR, Baker DA, Funk D, Lê AD, Shaham Y (2016) Stress-induced reinstatement of drug seeking: 20 years of progress. Neuropsychopharmacology 41:335-356. CrossRef Medline

Manvich DF, Webster KA, Foster SL, Farrell MS, Ritchie JC, Porter JH, Weinshenker D (2018) The DREADD agonist clozapine $N$-oxide (CNO) is reverse-metabolized to clozapine and produces clozapine-like interoceptive stimulus effects in rats and mice. Sci Rep 8:3840. CrossRef Medline

McFarland K, Davidge SB, Lapish CC, Kalivas PW (2004) Limbic and motor circuitry underlying footshock-induced reinstatement of cocaine-seeking behavior. J Neurosci 24:1551-1560. CrossRef Medline

McFarland K, Kalivas PW (2001) The circuitry mediating cocaine-induced reinstatement of drug-seeking behavior. J Neurosci 21:8655-8663. Medline

McFarland K, Lapish CC, Kalivas PW (2003) Prefrontal glutamate release into the core of the nucleus accumbens mediates cocaine-induced reinstatement of drug-seeking behavior. J Neurosci 23:3531-3537. Medline

Paxinos G, Watson C (2013) The rat brain in stereotaxic coordinates, Ed 7. Amsterdam: Elsevier Academic.

Preston KL, Epstein DH (2011) Stress in the daily lives of cocaine and heroin users: relationship to mood, craving, relapse triggers, and cocaine use. Psychopharmacology 218:29-37. CrossRef Medline

Refojo D, Schweizer M, Kuehne C, Ehrenberg S, Thoeringer C, Vogl AM, Dedic N, Schumacher M, von Wolff G, Avrabos C, Touma C, Engblom D, Schütz G, Nave KA, Eder M, Wotjak CT, Sillaber I, Holsboer F, Wurst W, Deussing JM (2011) Glutamatergic and dopaminergic neurons mediate anxiogenic and anxiolytic effects of CRHR1. Science 333:1903-1907. CrossRef Medline

Reinhard JF Jr, Bannon MJ, Roth RH (1982) Acceleration by stress of dopamine synthesis and metabolism in prefrontal cortex: antagonism by diazepam. Naunyn Schmiedebergs Arch Pharmacol 318:374-377. CrossRef Medline

Riegel AC, Williams JT (2008) CRF facilitates calcium release from intracellular stores in midbrain dopamine neurons. Neuron 57:559-570. CrossRef Medline

Rodaros D, Caruana DA, Amir S, Stewart J (2007) Corticotropin-releasing factor projections from limbic forebrain and paraventricular nucleus of the hypothalamus to the region of the ventral tegmental area. Neuroscience 150:8-13. CrossRef Medline

Seamans JK, Gorelova N, Durstewitz D, Yang CR (2001) Bidirectional dopamine modulation of GABAergic inhibition in prefrontal cortical pyramidal neurons. J Neurosci 21:3628-3638. CrossRef Medline

Shaham Y, de Wit H (2016) Lost in translation: CRF1 receptor antagonists and addiction treatment. Neuropsychopharmacology 41:2795-2797. CrossRef Medline

Silberman Y, Matthews RT, Winder DG (2013) A corticotropin releasing factor pathway for ethanol regulation of the ventral tegmental area in the bed nucleus of the stria terminalis. J Neurosci 33:950-960. CrossRef Medline

Speciale SG, Miller JD, McMillen BA, German DC (1986) Activation of specific central dopamine pathways: locomotion and footshock. Brain Res Bull 16:33-38. CrossRef Medline

Speert DB, MCClennen SJ, Seasholtz AF (2002) Sexually dimorphic expression of corticotropin-releasing hormone-binding protein in the mouse pituitary. Endocrinology 143:4730-4741. CrossRef Medline

Stefanik MT, Moussawi K, Kupchik YM, Smith KC, Miller RL, Huff ML, Deisseroth K, Kalivas PW, LaLumiere RT (2013) Optogenetic inhibition of cocaine seeking in rats. Addict Biol 18:50-53. CrossRef Medline

Stefanik MT, Kupchik YM, Kalivas PW (2016) Optogenetic inhibition of cortical afferents in the nucleus accumbens simultaneously prevents cueinduced transient synaptic potentiation and cocaine-seeking behavior. Brain Struct Funct 221:1681-1689. CrossRef Medline

Swanson LW (1982) The projections of the ventral tegmental area and adjacent regions: a combined fluorescent retrograde tracer and immunofluorescence study in the rat. Brain Res Bull 9:321-353. CrossRef Medline

Thierry AM, Tassin JP, Blanc G, Glowinski J (1976) Selective activation of mesocortical DA system by stress. Nature 263:242-244. CrossRef Medline Tseng KY, O'Donnell P (2004) Dopamine-glutamate interactions control- 
ling prefrontal cortical pyramidal cell excitability involve multiple signaling mechanisms. J Neurosci 24:5131-5139. CrossRef Medline

Ungless MA, Singh V, Crowder TL, Yaka R, Ron D, Bonci A (2003) Corticotropin-releasing factor requires $\mathrm{CRF}$ binding protein to potentiate NMDA receptors via CRF receptor 2 in dopamine neurons. Neuron 39: 401-407. CrossRef Medline

Van Pett K, Viau V, Bittencourt JC, Chan RK, Li HY, Arias C, Prins GS, Perrin M, Vale W, Sawchenko PE (2000) Distribution of mRNAs encoding CRF receptors in brain and pituitary of rat and mouse. J Comp Neurol 428:191-212. CrossRef Medline

Vranjkovic O, Gasser PJ, Gerndt CH, Baker DA, Mantsch JR (2014) Stressinduced cocaine seeking requires a beta- 2 adrenergic receptor-regulated pathway from the ventral bed nucleus of the stria terminalis that regulates CRF actions in the ventral tegmental area. J Neurosci 34:12504-12514. CrossRef Medline
Wanat MJ, Hopf FW, Stuber GD, Phillips PE, Bonci A (2008) Corticotropinreleasing factor increases mouse ventral tegmental area dopamine neuron firing through a protein kinase C-dependent enhancement of $I_{\mathrm{h}}$.J Physiol 586:2157-2170. CrossRef Medline

Wang B, Shaham Y, Zitzman D, Azari S, Wise RA, You ZB (2005) Cocaine experience establishes control of midbrain glutamate and dopamine by corticotropin-releasing factor: a role in stress-induced relapse to drug seeking. J Neurosci 25:5389-5396. CrossRef Medline

Westphal NJ, Evans RT, Seasholtz AF (2009) Novel expression of type 1 corticotropin-releasing hormone receptor in multiple endocrine cell types in the murine anterior pituitary. Endocrinology 150:260-267. CrossRef Medline

Williams CL, Buchta WC, Riegel AC (2014) CRF-R2 and the heterosynaptic regulation of VTA glutamate during reinstatement of cocaine seeking. J Neurosci 34:10402-10414. CrossRef Medline 